\title{
Dust impact on concentrated solar power: A review
}

\author{
Kacem Zereg ${ }^{1}$, Amor Gama ${ }^{+}$, Mounir Aksas ${ }^{3}$, Neelam Rathore ${ }^{4}$, Fatiha Yettou ${ }^{2}$, Narayan Lal Panwar ${ }^{4}$ \\ ${ }^{1}$ Laboratory of Applied Physics and Energy, Department of Physics, Faculty of Matter Sciences, University of Batna 1, 05000, Batna, Algeria \\ ${ }^{2}$ Unité de Recherche Appliquée en Energies Renouvelables, URAER, Centre de Développement des Energies Renouvelables, CDER, 47133, Ghardaïa, \\ Algeria \\ ${ }^{3}$ Higher National School of Renewable Energy, Environment \& Sustainable Development, 05078 Batna, Algeria \\ ${ }^{4}$ Department of Renewable Energy Engineering, College of Technology and Engineering, Maharana Pratap University of Agriculture and Technology, \\ Udaipur 313001, India
}

\begin{abstract}
Many sites with high solar radiation face high dust loads that reduce energy generation by concentrated solar power plants. This review presents the attenuative impacts of atmospheric aerosols, as well as reflectivity losses due to soiling of solar reflectors, by covering both experimental investigations and numerical studies; along with presenting the theoretical background. The chemical nature of aerosols, and the physics of soiling and atmospheric extinction phenomena (scattering and absorption) are also reviewed. Suspended particles like aerosols result in atmospheric extinction of the solar radiation that reaches the concentrators, and the deposition of these particles on the solar reflectors provokes decreases up to $80 \%$ in their reflectivity, and thus enhances the cumulus of optical losses and the reduction of energy production. Even though dust affects both CSP and photovoltaics, CSP technologies suffer more losses. The impact of dust should be particularly considered during the planning phase of solar thermal plants, since its consequent reduction in energy output can be severe. While there have been multiple papers to review dust-related problems for PV, the present paper is the first literature review dedicated to the impact of soiling on concentrated solar power.
\end{abstract}

Keywords: Aerosols, Concentrated solar power (CSP), Extinction, Reflectivity loss, Soiling, Turbidity

\section{Introduction}

During the last century, human activities resulted in a drastic increase in the amount of the atmospheric carbon dioxide [1-3]. To prevent global warming from rising above $1.5^{\circ} \mathrm{C}, 100 \%$ of the energy must be produced by transition to zero-emission in the upcoming years. Most of the energy should be generated using renewable energy [4-9]. Among the resources of renewable energy, solar energy is the most available one, and a feasible option for thermal energy applications [10, 11].

Concentrated Solar Power (CSP) technologies are very promising among the renewable energies and are growing fast, as they provide solutions to the decade's most alarming issues of global warming combined with shortage of energy, water and food [12]. The fuel of the solar thermal energy is the solar irradiance that penetrates the atmosphere and is concentrated by CSP plants. However, the presence of water vapor and suspended atmospheric particles (aerosols) attenuates the solar radiation, and affects both PV and
CSP technologies [13-17]. Also, the deposition of these particles on the collecting surfaces of the solar field provokes decreases in the reflectivity of solar mirrors and reduces the efficiency of thermal solar systems [18-20]. Therefore, being the common cause of the optical losses (extinction of irradiance and loss of reflectivity), aerosols are the most important factor that influences the exploitation of solar thermal energy (under clear-sky conditions). Not considering aerosols and dust will cause a significant uncertainty in the estimation of electricity production, and in the cost of large scale CSP projects [19, 21]. Moreover, since DNI is the fuel of CSP plants and small reflectivity losses result in serious drops in the plants' overall efficiency, losses of produced energy due to soiling are more important for CSP projects than other solar energy applications [21, 22].

Forecasting the presence of aerosols and the consequent attenuation will help in reducing extra-costs and optimizing the performance of CSP plants [23, 24]. For the solar tower system, losses due to attenuation can reach over $10 \%$ [24]. The optical losses
This is an Open Access article distributed under the terms of the Creative Commons Attribution Non-Commercial License (http://creativecommons.org/licenses/by-nc/3.0/) which permits unrestricted non-commercial use, distribution, and reproduction in any medium, provided the original work is properly cited.

Copyright (C) 2022 Korean Society of Environmental Engineers
Received July 24, 2021 Accepted November 11, 2021

${ }^{\dagger}$ Corresponding author

E-mail: gama.amor@gmail.com

Tel: +21329258157

ORCID: 0000-0003-1702-460X 
are enhanced further by the soiling of the solar reflectors [25]

Dust problems persist in the absence of better solutions, making research into aerosols-related issues critical for solar energy harvesting initiatives, particularly locations where there is no natural cleaning due to a lack of rain events. The aim of this paper is to review the studies that evaluated the effect of aerosols (suspended particles) and dust (deposited particles) on the performance of CSP technologies. The paper is organized as follows: in Section 2, previous informative literature reviews are presented, while Section 3 , the theoretical background, explains the physics of the different phenomena and the chemical nature of aerosols. In Section 4, recent research articles that treated the impact of dust on the exploitation of solar thermal energy are analyzed and reviewed, followed, in Section 5, by the review of the wide literature of the effect of different climatic parameters on the performance of CSP plants. The main effects are -as already mentioned- the attenuation of the solar irradiance and the drop in the solar reflector's optical efficiency. The range of the losses varies widely and depends on the sites surrounding CSP plants. In Section 6, the different mitigation approaches for soiling problems are presented and analyzed. The literature review is finalized with a summary (Section 7) and a conclusion on the losses caused by suspended and deposited dust particles. No previous studies reviewed the impact of dust on concentrated solar power, even though many papers reviewed the same issue for PV, which makes the present work the first literature review of this issue for CSP. Also, no previous review is available considering both of the optical losses, even though the extinction of solar irradiance and the soiling of solar reflectors are both caused by particles present in the vicinity of CSP plants. Since the phenomena are of common origin and occurrence, their negative impacts shouldn't be separated.

\section{Literature Reviews of Dust Impact on CSP}

Previous informative papers have reviewed the literature of the issue at hand; some were interested in the attenuative effect of the suspended aerosols, while others focused on the impact of soiling on mirrors. Hereafter, we present the focuses and conclusions of these reviews:

Sarver et al. [21] presented a comprehensive state of the art covering studies of dust impact on solar energy (PV and CSP) between 1942 and 2013 and different measures to reduce the losses. The authors concluded that even though energy yield is reduced by dust for both PV and CSP, CSP is more affected since small reflectivity losses would result in major thermal losses (loss range: CSP, $20-50 \%$ compared to PV, 15-30\%).

Ghazi et al. [26] reviewed the soiling of flat surfaces and noted that despite the high solar intensity available in many regions of the world, these regions host high aerosols loads, especially the MENA region. It was reported that solar devices should be inclined at an angle to the horizontal, no matter how small the angle is, in order to avoid the maximum soiling characterizing the horizontal position. As mitigation, it was recommended that CSP mirrors should be set to zero pitch angle early in the morning or late in the evening, so that the dust would slip off.

Costa et al. [27] authored a complete review of the literature of soiling-related solar energy issues for the period between 2012 and 2015, and updated it for 2016, but only few research papers were concerned by CSP soiling [28]. They highlighted the growing number of studies concerning the issue and presented a reference-listing table of the papers during the period of interest, many of the papers were concerned with PV soiling, compared to the fewer number of papers studying CSP soiling.

Hanrieder et al. [29] reviewed the approaches of estimating the atmospheric extinction in solar tower plants, inputs were obtained from on-site measures or satellite data. It was reported that power losses due to atmospheric extinction by scattering and absorption are considerable and highly dependent on the geometry and size of the heliostats field, the receiver, and the local atmospheric conditions (especially sites with high aerosols or water vapor presence). The authors recommended plant optimization design using time series of the atmospheric extinction (based on in-situ measurements) instead of the usual models.

Bouaddi et al. [30] reviewed the methods of cleaning soiled CSP reflectors like water-based methods, ultrasonic cleaning, dry cleaning methods, etc. Dry cleaning methods include coatings, electrodynamic screens (EDS), shaking, vibrating and applying high voltage to the reflectors. It was reported that ultrasonic cleaning uses 7 times less water than pressurized water cleaning.

Antonanzas-Torres et al. [31] authored a review of seventy clear-sky irradiance (CSI) models. The input data were obtained from the Baseline Surface Radiation Network (BSRN) and Aerosols Robotic Network (AERONET). Only 8 models got Root Mean Square Error (RMSE) less than 5\%, 7.5\% and 10\% for Global Horizontal Irradiance (GHI), Diffused Irradiance (DI), and Direct Normal Irradiance (DNI) resp; and thus, were considered best models in Cabauw (Netherlands) and Carpentras (France).

In the present paper, we review the literature of dust impact on CSP. Even though this issue was reviewed for PV (like the recent review paper by Kazem et al. [11]), no previous literature review was dedicated to the consequences of soiling on CSP plants, thus the present up-to-date paper. Also, no review (and few research papers like [18]) linked the impact of atmospheric extinction to soiling problems despite the proved relationship between the two phenomena. Finally, we highlight in our paper insights and recommendations about research necessities regarding the issue at hand.

\section{Theory}

\subsection{Chemical Nature of Aerosols}

An aerosol is generally defined as a suspension of liquid or solid particles in a gas, with particle diameters in the range of $10^{-9}$ to $10^{-4} \mathrm{~m}$. In scientific research, the term Particulate Matter (PM) refers to particles with aerodynamic diameters $\leq 1 \mu \mathrm{m}$ (PM1), $\leq$ $2 \mu \mathrm{m}$ (PM2) or $\leq 10 \mu \mathrm{m}$ (PM10). In the troposphere (lower atmosphere), particles' mass and number concentrations vary from 1 to $100 \mu \mathrm{g} / \mathrm{m}^{3}$ and from $10^{2}$ to $10^{5}$ particle $/ \mathrm{cm}^{3}$ resp [32, 33]. Atmospheric aerosols differ widely in composition as a result of the diverse natural and anthropogenic origins: Carbonaceous Aerosols (CA) are constituted of Black Carbon (BC) and Organic Carbon (OC). OC is emitted from biomass burning (eg: forest fires) 
and transported biological materials (eg: wastes of animals \& plants). $\mathrm{BC}$ is the inorganic black carbon (also known as elemental carbon), its main source is fossil fuels' combustion [32]. Similarly, sulfur is a consequence -and an indicator- of hydrocarbon combustion and industrial activity, it is the result of long-range transport processes and continuous conversion to secondary particulate sulfur [32, 34].

Dust and sea salt are common species of atmospheric aerosols that are considered in simulation models (eg: [35]), dust presence in the atmosphere attenuates the solar energy and reduces the efficiency of CSP plants [14, 20], the main components of desert dust are quartz and calcite rich in silicon and calcium resp (eg: Egypt [34], Morocco [36]), while the existence of silicon is due to disturbances of desert soil by wind or human activity, calcium originates from industrial and/or building activities [34].

In the present paper, we are concerned with the attenuation of solar irradiance by natural aerosols (also referred to as: dust/soiling). Generally, the physical properties of the atmospheric aerosols are determined using the following techniques [32]: Differential Mobility Analysis (DMA), inertial separation, Scanning/ Transmission Electron Microscopy (SEM/TEM), light scattering (Mie), Spectrophotometry, Photoacoustic Spectroscopy, and Nephelometry for absorption and scattering coefficients.

\subsection{Physics of Aerosols' Behavior}

\subsubsection{Extinction of solar irradiance (scattering and absorption)}

When the solar energy penetrates Earth's atmosphere, a part of the incident energy is lost by scattering and absorption, especially when the sky is turbid (Fig. 1) [37]. Scattering of irradiance is primarily due to aerosols [38], and happens at all wavelengths, a part of the scattered radiation is sent back to the outer space while the other part, the diffuse radiation, is scattered towards the ground. The solar radiation -unaffected by the scattering phenomenon- that reaches directly from the solar disk is the direct (or beam) normal irradiance DNI [37, 39]. Absorption happens only at selective wavelengths, the short-wave UV radiation below $0.29 \mu \mathrm{m}$ is absorbed by atmospheric Ozone, while CA Carbon dioxide absorbs long-wave Infra-Red radiation [37, 39, 40]. Aerosols' optical effect is much more scattering than absorbent, according to Pettit and Freese [41].

\subsubsection{Soiling of solar reflectors}

Dust is lifted off the ground; by the wind, and suspended in the air when the momentum of aerodynamic drag and lift forces is more important than the momentum of gravity and inter-particle forces [20], the vertical diffusion of aerosols in the air is caused mainly by the atmospheric turbulence, Brownian motion and gravity (see Fig. 2) [35]. When gravity becomes important, dust particles fall on concentrators of the solar field [42], another situation during which important soiling occurs is the windy (hazy) weather, not because higher wind speeds entrain more dust into the air, rather, the increase of soiling is because stronger wind exposes the reflectors to air flow with greater concentration of aerosols per unit of time [43]. Only dry dust deposition is considered since wet deposition happens during precipitations, which have a predominant cleaning effect [44].

Dust deposition is described by its most representative physical quantity: dust deposition flux $\mathrm{F}_{\mathrm{d}}$

$$
F_{d}=C_{d} \times v_{d} \cos \left(\alpha_{t}\right)
$$

where $C_{d}$ is the dust concentration in the air $\left(\mu \mathrm{g} / \mathrm{m}^{3}\right), v_{d}$ is the deposition velocity of particles and $\alpha_{t}$ is the tilt angle of the solar collector [44], $F_{d}$ represents the amount of dust that vertically falls on the reflector. $v_{\mathrm{d}}$ is the sum of $v_{\mathrm{g}}$ and $v_{\mathrm{t}}, v_{\mathrm{g}}$ is the velocity of aerosols falling freely in the fluid (air in this case) under the equilibrium of gravity and dragging forces, $v_{\mathrm{t}}$ is the velocity resulting from turbulence, diffusion and impaction, it depends mainly on the Brownian motion [44]:

$$
\begin{gathered}
v_{d}=v_{g}+v_{t} \\
v_{t}=\left(r_{a}+r_{b}\right)^{-1}
\end{gathered}
$$

In Eq. (3) $r_{a}$ and $r_{b}$ are respectively the aerodynamic and the quasi-laminar Brownian diffusion resistances. The detailed theory of dust deposition flux is given by Picotti et al. [44]

Aerosols particles are attracted and held to the mirrors' surfaces by the adhesive forces: Van der Waals, electrostatic and capillary forces [42, 44]; even though the surface is tilted, the particles are

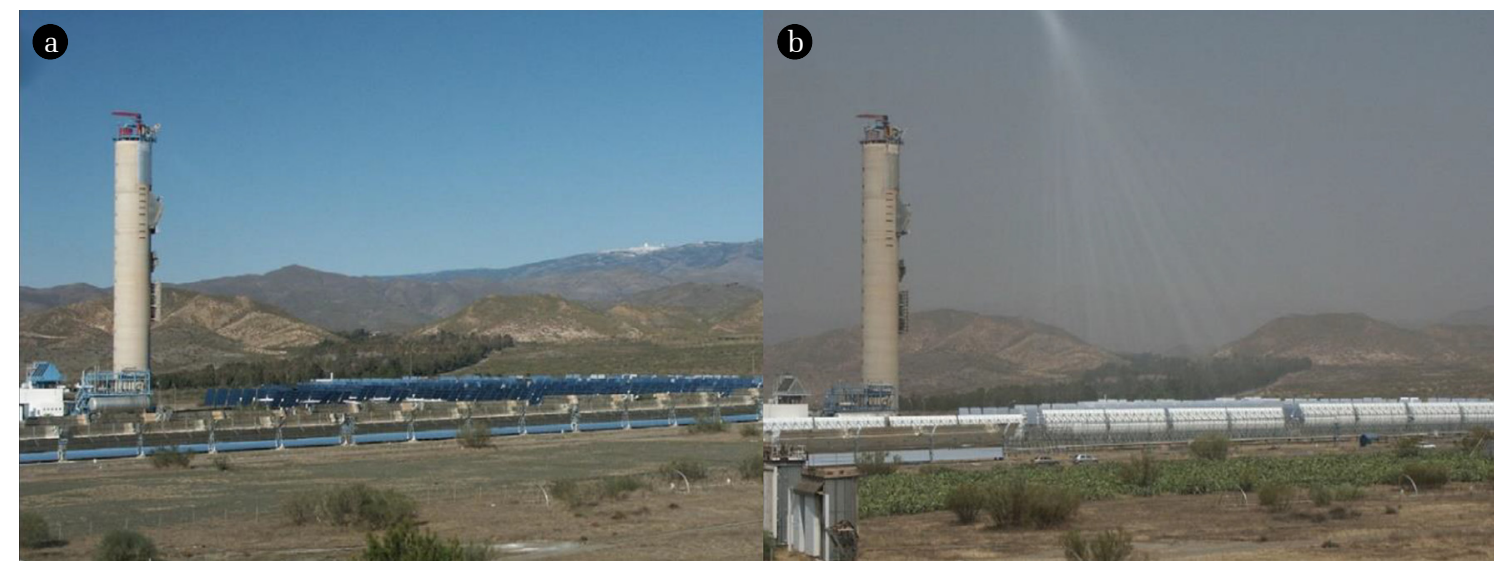

Fig. 1. Central tower plant CESA 1 at PSA (Spain) on (a) a clear day and (b) a hazy day [29]. 


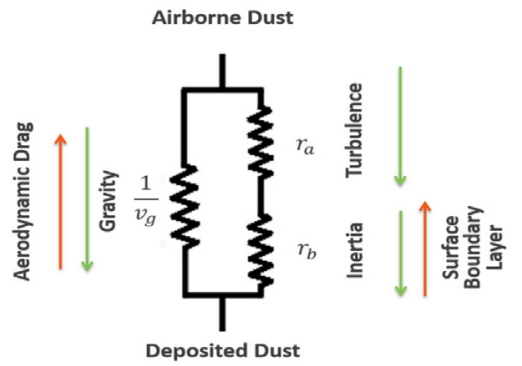

Fig. 2. Different forces acting on aerosols mid-air [44].

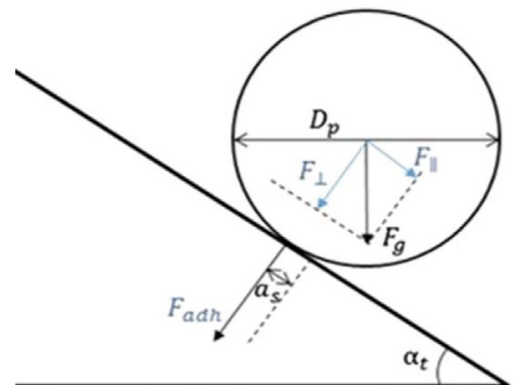

Fig. 3. Aerosols are attached to tilted surfaces due to adhesive forces $F_{\text {adh }}$ [44].

not detached because the aforementioned adhesive forces are thousands of times stronger than the gravity component which is parallel to the surface, see Fig. 3 (the perpendicular component contributes to the adhesion) [45].

The removal of aerosols is generally due to natural washing by precipitations [36, 44], or to the action of the drag forces increased by increasing wind speed which, furthermore, generates turbulence eddies that contribute to the removal as well [43]. Humidity, however, prevents the removal of soiling through capillary forces, above certain values of relative humidity $\mathrm{RH}$ (70\% to $80 \%)$ it's very difficult for the removal by wind to happen [43, 46, 47].

\section{Recent Research and Advances in Dust Impact on CSP}

\subsection{Effect of Soiling on Solar Reflectors}

Since the most recent review paper reviewed the up-to-2016 literature of the impact of dust on solar energy (including thermal solar energy) [28], we review in this subsection the papers that studied dust deposition on solar reflectors and were published in 2017 or later.

To assess the impact of dust deposition on the CSP plant's energy output, Alami Merrouni et al. [48] used Ebsilon software. Without consideration of soiling, the energy yield in Morocco and Portugal was 1.4 GWeh and 1.3 GWeh resp, but with consideration of soiling, both sites produce comparable electricity supply of 1.25 GWeh during the exposure period, this is expected given the higher soiling in Morocco compared to Portugal [48, 49]. Azouzoute et al. [50] evaluated the impact of soiling on energy production of a $5 \mathrm{MW}$

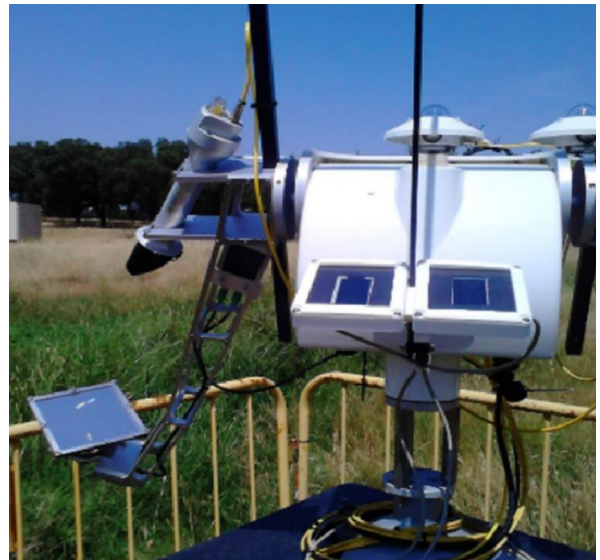

Fig. 4. The solar tracker used to measure the cleanliness [52].

plant. The cleanliness index dropped by up to $30 \%$ in just 8 days. Also, different meteorological parameters were measured for one year, the data were implanted in System Advisor Model (SAM), two weeks of soiling caused average daily production loss of $22 \%$. While Hachicha et al. [51] reported 36\% decrease in the thermal efficiency of parabolic trough collectors in UAE due to a reflectivity drop of $63 \%$ (3 months of exposure). Also, dust caused more loss in CSP than PV by a factor of 3 to 5 , and was correlated to wind speed and direction. Whilst in Portugal, soiling rate was reported to be 8 to 14 times higher for CSP than for PV for an identical quantity of soiling according to Bellmann et al. [52]. Based on Mie-scattering and the various cleanliness and incidence angle measurements (Fig. 4), a model that evaluates the optical losses due to soiling for both CSP and PV was developed.

Bouaddi et al. [53] analyzed soiling's effect on different types of CSP mirrors; glass reflectors recover perfectly their reflectivity after rain, better than aluminum ones; however, glass mirrors tend to lose their reflectivity faster. Also, clean mirrors were soiled faster than unclean ones. The highest soiling rate was recorded for glass mirrors in August: $-2.3 \%$ per day, by the summer's end, the mirrors lose up to $73 \%$ of cleanliness. A similar study was done by Wiesinger et al. [54] and the mirrors' average reflectance losses were $36.9 \%$ for aluminum and $\mathbf{1 0 . 8 \%}$ for glass. Azouzoute et al. [55] confirmed that aluminum mirrors were less soiled than glass mirrors, their maximum soiling rate was $25 \%$ in comparison with $35 \%$ for glass ones. Authors recommended aluminum mirrors for CSP plants, especially in arid regions for industries with low temperature needs.

The severity of dust deposition does not vary only with the solar mirror's material type, but also with the different climates and regions hosting the CSP plants: Sansom et al. [56] run a comparative study in Algeria, Iran and Libya. Only aerosols smaller than $250 \mu \mathrm{m}$ adhered to mirrors. Dust particles up to $1 \mathrm{~mm}$ can be lifted by strong wind and damage the surface, thus particles larger than 250 microns should be used in laboratory erosion simulations. Guerguer et al. [57] (Morocco, 3 years) compared soiling between seaside and desert sites: mirrors exposed in the seaside were more soiled than those in the desert. The reflectivity losses were up to $80 \%$ (August) for seaside site and 23\% (March) for desert site. More than $80 \%$ of the deposited particles were smaller than 30 microns. In a similar coast/desert comparison, Endaya et al. [58] simulated -by accelerated 
tests- the impact of dust on a CSP reflector in Libya. The fine coastal dust caused more optical losses than the desert's one: the reflectivity losses were $8 \%$ and $4 \%$, respectively.

Long-range aerosols-transport phenomena can also cause soiling, Conceição et al. [49] compared soiling of mirrors in Portugal and Morocco, the daily dirtiness rates were 0.013 in Morocco and 0.004 in Portugal. Red rain in Morocco caused reflectance drop by $19.7 \%$ in one day. Similarly, Alami Merrouni et al. [48] reported high soiling rates of 10 to $21 \%$ in Morocco compared to 3 to $7 \%$ in Portugal. In a wider comparison, Wiesinger et al. [59] run 1 year of exposure in six CSP-potential sites in Spain, Morocco and Chile, as well as accelerated aging tests with an open-loop setup. An erosion potential risk matrix is proposed and validated in 5 sites, the matrix has 6 meteorological and geological parameters as inputs. Likewise, Wiesinger et al. [60] studied the erosion risk of reflectors in Morocco and Kuwait. The maximum loss of the specular reflectance of mirrors was in Kuwait: $42.5 \%$ in just 9 months (in Morocco only $5.9 \%$ after 25 months). Matal et al. [61] performed erosion simulations. The reflectivity loss is proportional to air velocity and tilt angle, the reflectivity loss due to erosion at $90^{\circ}$ was greater than that at $45^{\circ}$ (for $25 \mathrm{~m} / \mathrm{s}$, the optical losses were $11.03 \%$ and $5.31 \%$ resp). Recently, in 2021, Wiesinger et al. [62] investigated the effect of height and orientation on the erosion of solar mirrors. The erosion intensity decreased with increasing height and increased with the increasing tilt angle. Also, short, strong wind events caused more intense erosion than the more frequent, moderate events. Buendía-Martínez et al. [63] established a lifetime prediction model for solar reflectors, based on accelerated aging tests and outdoor exposure at 10 sites. The model considers the effect of corrosion, erosion and soiling by combination of the results of both tests.

Some studies were interested in the relationship between the deposited dust's weight, and the consequent reflectance drop: Zhao et al. [64] studied soiling of Fresnel linear reflectors in China. After 48 days, dust density of $2.5 \mathrm{~g} / \mathrm{m}^{2}$ caused $9.4 \%$ loss in average relative reflectivity. The soiling was maximal for the horizontal position (9.19\%) and minimal for the vertical one (0.72\%). A model for the cleanliness factor was developed with about $1 \%$ standard deviation. Another study in China was done by Wu et al. [65] to assess the soiling of a parabolic trough collector. After a month, the collector's bottom edge was more soiled and lost more reflectivity $\left(1.03 \mathrm{~g} / \mathrm{m}^{2}, 15 \%\right)$ than the top edge $\left(0.83 \mathrm{~g} / \mathrm{m}^{2}, 12 \%\right)$. More severe losses were reported by Azouzoute et al. [66] in Morocco. The highest soiling loss rate was after two weeks: $39 \%$, correlated with a deposition density of $0.8 \mathrm{~g} / \mathrm{m}^{2}$. Usamentiaga et al. [67] studied the impact of soiling on the reflectivity in the visible and infrared spectra, with 6 different pollutants. The pollutants weight varied from $0.1 \mathrm{~g}$ to $5 \mathrm{~g}$. For some pollutants, the reflectivity was higher than the clean surface, this due to the opposite optical behaviors of these pollutants between infrared and visible domains.

An efficient way to bypass the aforementioned experimental studies is by developing models -on physical bases- that evaluate the soiling of CSP reflectors, like the one validated by Picotti et al. [44] which considers: dust deposition rate, gravity, diffusion and turbulence, Brownian motion, aerodynamic drag and van der Waals forces, the model considers also dust shading and blockage effects; the model's details can be found in ref. [44]. The inputs are: aerosols concentration and size distribution, mirrors' position, wind speed and ambient temperature. The average relative error is $14 \%$ for the $45^{\circ}$ tilt. A model considering incidence angles' impact on the optical efficiency of CSP plants was developed and validated by Heimsath \& Nitz [68]. It showed proportionality between incidence angles and the intensity of scattering by aerosols, and inverse proportionality to specular reflectivity. The optical efficiency of parabolic trough reflectors in Spain was found to be overestimated by $1.5 \%$. Wu et al. [65] proposed a model to predict dust characteristics and tilt angles' influence on the soiling rate; the model is validated, with a less than $3 \%$ standard deviation, by the measured cleanliness of a parabolic trough collector in China. Similarly, Heimsath et al. [69] proposed a model that considers the effects of variable reflectance angles and soiling rates.

In addition to natural dust, bird droppings contribute to the soiling of solar mirrors as well and result in serious reflectivity drops [64, 65], the losses in the overall performance might even reach $60 \%$ [67]. The severity of the losses due to bird droppings makes them comparable to major soiling losses such as localized dust deposition and red rain events [48, 49].

Finally, according to Vicente et al. [70] (Spain, 2 years), the application of anti-soiling coatings to the solar mirrors is of positive effect. They confirmed tilt angle and soiling to be inversely proportional.

In Table 1, we present studies that proposed interesting methods and instruments to measure the soiling rates of CSP reflectors.

Table 1. Summary of Recent Studies Proposing Different Methods and Devices to Measure CSP Reflectors' Soiling Rates

\begin{tabular}{|c|c|c|}
\hline Investigation & Location, duration & Main results \\
\hline Wolfertstetter et al. [71] & Spain, 4 weeks & $\begin{array}{l}\text { Presentation of a new device to measure soiling rates of a parabolic trough's } \\
\text { tube receivers. }\end{array}$ \\
\hline Guerguer et al. [72] & Morocco, 3 years & $\begin{array}{l}\text { Neural network modeling can be trained to predict with high precision the } \\
\text { reflectance loss. High wind speed and humidity are causes of high soiling rates. }\end{array}$ \\
\hline Le Baron et al. [73] & France, 1 month & $\begin{array}{l}\text { Development of a novel instrument to measure solar mirrors' soiling rates and } \\
\text { reflectance for various values of incident and detection angles. }\end{array}$ \\
\hline Wolfertstetter et al. [74] & Spain, 7 months & $\begin{array}{l}\text { Development of TraCS4 a tracking cleanliness sensor to monitor } 4 \text { different } \\
\text { reflectors' cleanliness at the same time. }\end{array}$ \\
\hline Wolfertstetter et al. [75] & Spain, 8 weeks & $\begin{array}{l}\text { Introduction of a soiling measurements method, this new method uses camera } \\
\text { signals treated with QFly software. }\end{array}$ \\
\hline
\end{tabular}




\subsection{Aerosols' Attenuation of Solar Irradiance}

The optical losses in CSP plants result from the cumulus of two overlapping phenomena: the reflectivity loss due to dust deposition and the attenuation (extinction) of DNI by suspended aerosols, aerosols' suspension results from the uplift of dust particles by wind, and dust deposition results from aerosols' settling, thus the atmospheric turbidity should also be evaluated when studying the risk of soiling in CSP sites because reflectivity and AOD are inversely proportional as reported by Raillani et al. [18] (Morocco, 1 year) who confirmed decreasing reflectivity when AOD increases. This supports the proposition of Griffith et al. [46] who recommended the monitoring of AOD around CSP plants to assess the risk of soiling, especially for plants near industrial zones.

AOD is important for extinction assessment, especially in solar tower plants: Polo et al. [76] (PSA, 2 years) used the data of two high-resolution cameras to improve Polo extinction model [77] for central tower plants. The model was validated with AOD data of the nearby AERONET station. The improved model has $6.1 \%$ of RMSE (previously 10.9\%). Similarly, Carra et al. [78] developed and validated an Extinction AOD method using extinction data at PSA. The data were used to validate AERONET and MERRA2 datasets, as well as the data of MODIS Aqua and Terra satellites. Hanrieder et al. [79] (Spain and Morocco, 35 months) also studied the transmittance in solar tower plants and validated a model [80] for $1 \mathrm{~km}$ slant range. Aerosols were described by three approaches: Homogenous distribution, Vertical aerosols profiles of LIVAS database [81] and The Boundary Layer Height [82]. The average broadband transmittance was 0.89 for PSA (Spain), 0.87 , and 0.86 for the Moroccan sites. Statistical parameters were $\mathrm{MBE}<5 \%$ and RMSE $<8 \%$, which reflects the good model fitting.

Turbidity parameters (mainly AOD) are crucial for the prediction of DNI by CSI models as the models' performance varies globally due to AOD variations. Ruiz-Arias and Gueymard [22] compared 15 frequently cited CSI models. AOD's effect on DNI was more important than Pw's. DNI inter-model discords are higher and broader than GHI, especially in Asia, MENA and Central Africa. Large DNI discords are more apparent for extreme solar zenith angles, these deficiencies are related to extreme solar altitudes and would not affect most solar applications. Benkciali et al. [83] (Algeria, 3 years) studied 18 CSI models under different climates. The best models were: ESRA, Dogniaux, MAC and Yang. Turbidity parameters $\left(\mathrm{T}_{\mathrm{L}}, \mathrm{AOD}, \alpha\right.$ and $\beta$ ) were found to have the most important impact on the models' accuracy. Simple models over-estimated the DNI, while others underestimated it. Grosjean et al. [84] (10 sites worldwide, 1 year) reported that ASTM spectrum [85] has a tendency of underestimating AOD. The difference between the solar spectrum calculated with ASTM and the data from 10 AERONET stations is less than $0.1 \%$.

Satellites-derived AOD data might become dependable inputs for CSI models: Goto et al. [35] studied the data measured by two next-generation satellites. The agreements with AERONET were high to moderate, thus the data are reliable. The satellites could detect a large load of aerosols which no other device could detect. Yet satellites cannot retrieve AOD of areas with thick clouds or high surface-albedo. Bright and Gueymard [86] (452 AERONET stations, 18 years) validated the AOD data monitored by MODIS
Aqua and Terra satellites. Their combination offered more precise AOD values than those given separately by Aqua or Terra. Both satellites lack the accuracy for solar energy applications, notably for a decisive parameter like AOD.

Many authors -worldwide- developed local CSI models with high to acceptable accuracy. Behar et al. [87] (Chile, 1 year) proposed and validated a method to predict solar energy and atmospheric turbidity using meteorological inputs. The respective MBE of DNI and $\mathrm{T}_{\mathrm{L}}$ are $0.91 \%$ and $1.31 \%$, which shows the accuracy of the model despite its simplicity. In Northern Africa, Marif et al. [88] (Algeria, 31 months) studied the turbidity and developed a CSI model, they confirmed that $\mathrm{T}_{\mathrm{L}}$ and $\beta$ are highly affected by wind speed, ambient temperature, and humidity. Aerosols' loads were high in summer and low in winter. The mean $\mathrm{T}_{\mathrm{L}}$ and $\beta$ were 3.63 and 0.094 resp, while the highest values were 5.07 and 0.159. Capderou's Linke turbidity formula [89] was validated, and was judged suitable for low altitudes. In Asia, Rathore et al. [39] (India, 8 years) generated a clear-sky solar map of India; they validated the r.sun model. The GHI, DNI and DI were calculated with low MBE under the value of $\pm 10 \%$ recommended by [90], thus the r.sun model is qualified to compute the irradiation in India. Yu et al. [91] (China, 84 sites) studied the radiative effect of aerosols and water vapor, and used datasets to simulate the radiative effect with a RMSE of $9.00 \%$. A consistency is observed between the 15 years averaged distribution of AOD and that of aerosols' radiative effect; the yearly radiative effect was $0.51 \mathrm{~W} / \mathrm{m}^{2}$ (3.35\% over 15 years). In Europe, Abreu et al. [92] (Portugal, 10 years) validated a CSI model with AERONET and BSRN datasets. Yang [93] (SURFRAD network, USA, 4 years) proposed a new factor to evaluate CSI models, namely: the mean square error scaling.

Bright et al. [94] (5 BSRN sites, 3 years) developed a global clear sky detection model. The model performed well under five different climatic zones and overcame the limitations observed in other models (eg: poor performance under high zenith angles). The model is freely available and coded in Matlab. Also, Bright et al. [95] provided access to reanalysis data for CSI modelling through a free python package of MERRA-2.

\section{Effect of Dust Deposition and Climate Parameters on CSP Performancce}

\subsection{Effect of Soiling on Reflectors}

To evaluate the impact of dust on solar tower plants, Singh et al. [96] investigated the soiling of heliostats and Open Volumetric Air Receivers (OVAR), the tests were done with single and double heliostat set-ups. Dust blocked 20\% of the OVAR's pores, which caused reduction of the convective heat transfer and the overall efficiency. For the single heliostat and the first one of the double-heliostat set-up, the deposition of dust was uniform, for the second heliostat, the deposition was localized due to the turbulent flow caused by the first heliostat. The effect of soiling on a parabolic trough power plant was studied by Niknia et al. [97], 44\% and $60 \%$ reflectance losses were observed after 44 days and two months resp, the same losses were correlated with dust weights of $1 \mathrm{~g} / \mathrm{m}^{2}$ and $1.5 \mathrm{~g} / \mathrm{m}^{2}$ resp. The following empirical energy loss correlation 
was given as a function of the deposited dust thickness:

$$
\Delta Q / Q=0.367 \ln \left(\delta_{2}\right)+0.7249
$$

Factors such as the tilt angles of solar reflectors or their exposure direction have an impact on the intensity of the soiling. Alami Merrouni et al. [36] evaluated this effect for different materials of solar reflectors. The monthly cleanliness drops of the horizontal mirrors were $45 \%$ and $33 \%$ for glass and aluminum resp, while for $+45^{\circ}$ mirrors the drop was $14 \%$ for both materials, the $0^{\circ}$ (vertical) and $-45^{\circ}$ (ground-facing) mirrors remained clean (3\% drop). An important soiling factor highlighted by the authors was the wind direction. Similarly, Griffith et al. [46] studied soiling of tilted mirrors at a candidate CSP site. The soiling of the horizontal mirrors was twice the $+45^{\circ}$ ones and the mean reflectivity loss was $0.5 \%$ per day. Other similar studies on the effect of reflectors' material, tilt and direction on the intensity of soiling can be found in table II [98-101].

Bouaddi et al. [102] modeled the cleanliness of CSP reflectors with Dynamic Linear Models, then compared it with that of exposed $45^{\circ}$ tilted mirrors; the dust distribution was homogenous (as noted also by [96, 103]); the lowest measured cleanliness was around $20 \%$ after 3 months. The local linear trend was the best to describe the cleanliness factor. Other models are proposed in Table 2 [104, 105].

Finally, even though most of the soiling is due to the deposition of dust, many authors highlighted other sources of optical losses due to soiling, mainly bird droppings (eg: [46, 106]).

To sum up, dust deposition is non-negligible and can cause energy losses up to $88 \%$ [107] and reflectivity losses up to $80 \%$ [102], the soiling rate depends upon the wind direction and the exposure direction of the reflectors [36, 46, 108], and their placement within the solar field, in particular, first-row reflectors suffer from uniform soiling and are soiled more than the rest of the solar field [96, 102, 103]. These are important factors to consider when planning optimal cleaning schedules that keep the efficient reflectors' performance at good levels. To assess the risk of soiling, monitoring climatic parameters at CSP sites is crucial, namely: AOD [46], precipitations [36, 108], wind speed and direction [108], and relative humidity [53]. Tilted reflectors are less soiled, and glass mirrors -compared to other materials- lose their reflectivity faster and restore it better after cleaning, these properties are helpful in sites where frequent cleaning is possible [36, 46, 98]. Erosion experiments should include dust particles larger than $250 \mu \mathrm{m}$, since these particles can be lifted and deposited on the surfaces of reflectors or cause their erosion $[43,56]$.

\subsection{Aerosols' Effect on Solar Irradiance}

Clear-sky irradiance (CSI) is affected by various parameters and CSI modeling is crucial for proper exploitation of solar energy. Ineichen [109] validated seven CSI models over eight years at 22 locations in Europe, Africa and Asia. Parameters other than AOD and $\mathrm{Pw}$ have minor effects on irradiation. The three best models were: Solis, REST2 and McClear. Ineichen and Perez [110] provided an air-mass-independent formulation for $\mathrm{T}_{\mathrm{L}}$ in order to bypass the $\mathrm{T}_{\mathrm{L}}$ 's dependence upon solar geometry. The developed $\mathrm{T}_{\mathrm{L}}$ formulation is independent of altitude and AM (Eq. (5)), and is coherent with the previous studies for $\mathrm{AM}=2$.

$$
T_{L I}=\left(11.1 \ln \left(b \times I_{0} / D N I\right) / A M\right)+1
$$

$\mathrm{I}_{0}$ is the solar constant, $\mathrm{b}$ is a multiplicative factor and $\mathrm{AM}=2$.

Several papers studied the attenuation of solar energy due to aerosols, like the study of Singh et al. [111] in India. Hazy skies caused very high mean AOD of 1.17; for very hazy days AOD was up to 3.08; high AOD values are associated with close to zero $\alpha$ values, which indicated the dominance of coarse particles; the average $\alpha$ was 0.328 and the lowest $\alpha$ was -0.06 (negative $\alpha$ was correlated with the presence of water insoluble dust). The attenuation of solar irradiance by dust had an average value of $-13.6 \pm 1.4 \mathrm{~W} / \mathrm{m}^{2}$ for every 0.1 increase in $\tau_{500}$. In Malta, Bilbao et al. [112] quantified the attenuation of the solar shortwave radiation SW (especially UV, the most energetic fraction of SW radiation), they found that an AOD unit causes UV radiation attenuation by $-28.12 \%$ to $-52.42 \%$, while the absorption of the global SW by the water vapor column was between -2.44 and $-4.53(\% / \mathrm{cm})$. Haywood et al. [40] evaluated the top of atmosphere (TOA) radiative effect of the Saharan dust in West Africa, the attenuation of DNI during dust events was as much as $-60 \pm 5 \mathrm{~W} / \mathrm{m}^{2}$; also, measurements of aerosols' optical properties were in agreement with Mie's scattering theory.

Tahboub et al. [113] elaborated a model that evaluates heliostats-receiver irradiance attenuation in UAE, four pyrheliometers recorded one year of data (see Fig. 5), the data were filtered for various reasons (eg: night data, shading) and $55.8 \%$ of the recorded data were selected, the model is based on the Beer-Lambert equation and the attenuation of irradiance is as follows:

$$
D N I_{n}=D N I_{4} \exp (-X \times d)
$$

$\mathrm{DNI}_{\mathrm{n}}$ is measured by stations 1,2 , or 3 , " $\mathrm{X}$ " and " $\mathrm{d}$ " are, resp, the extinction coefficient and the distance between station $\mathrm{n}$ and 4. This model is similar to the one of Sengupta and Wagner [24] although the later was not validated at a specific site according to [113].

Cardemil et al. [38] compared the sizing of a solar tower plant in Brazil by different CSI models, while Pitman \& Vant-Hull was in agreement with Sengupta \& Wagner, DELSOL didn't agree with both, the Power Tower Generator (PTGen) program that was used

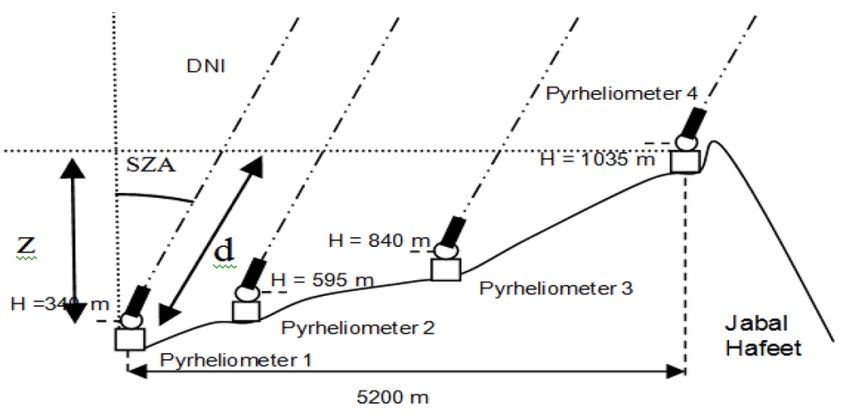

Fig. 5. Representative scheme of the placement of the four pyrheliometers on Jabal Hafeet mountain [113]. 


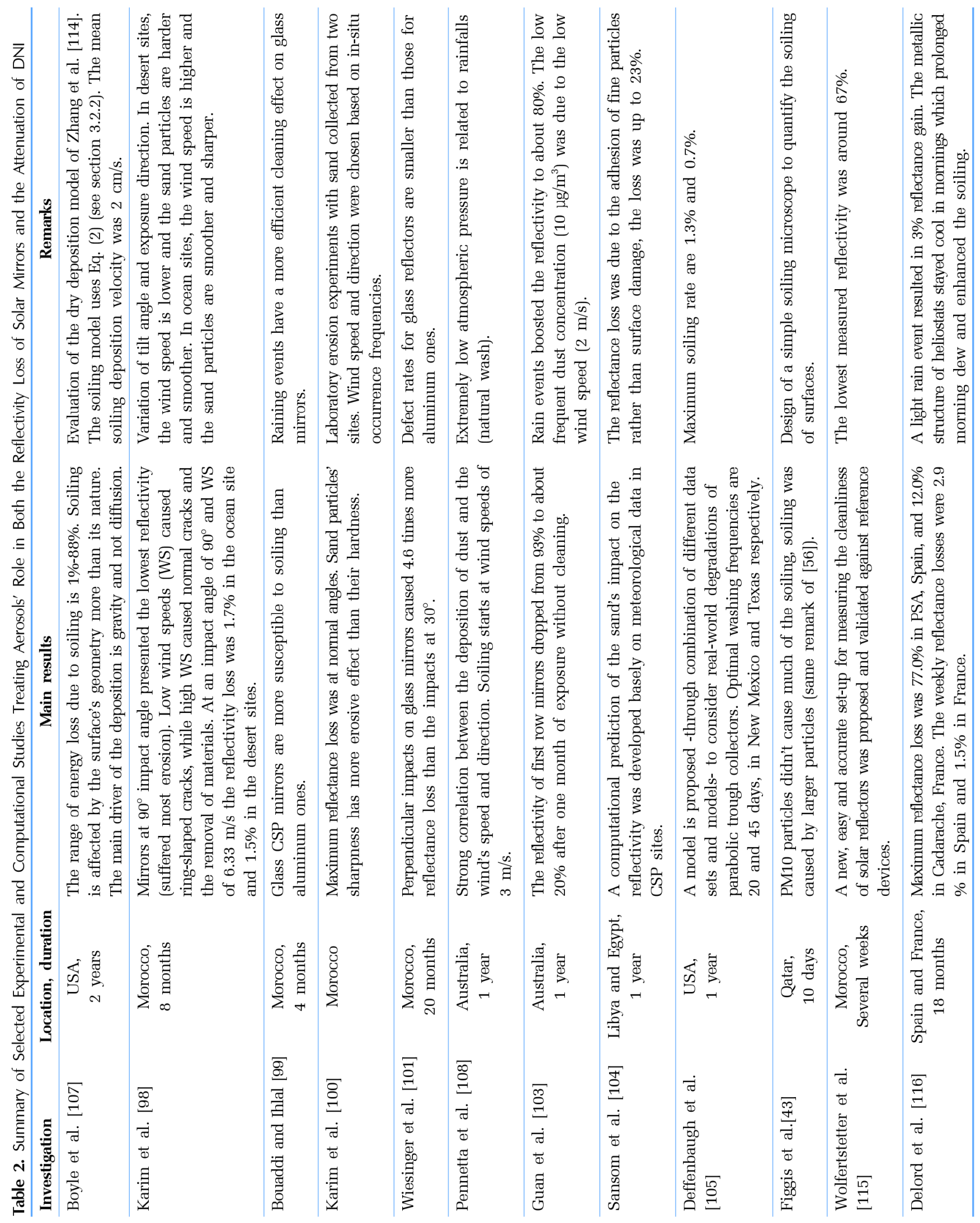




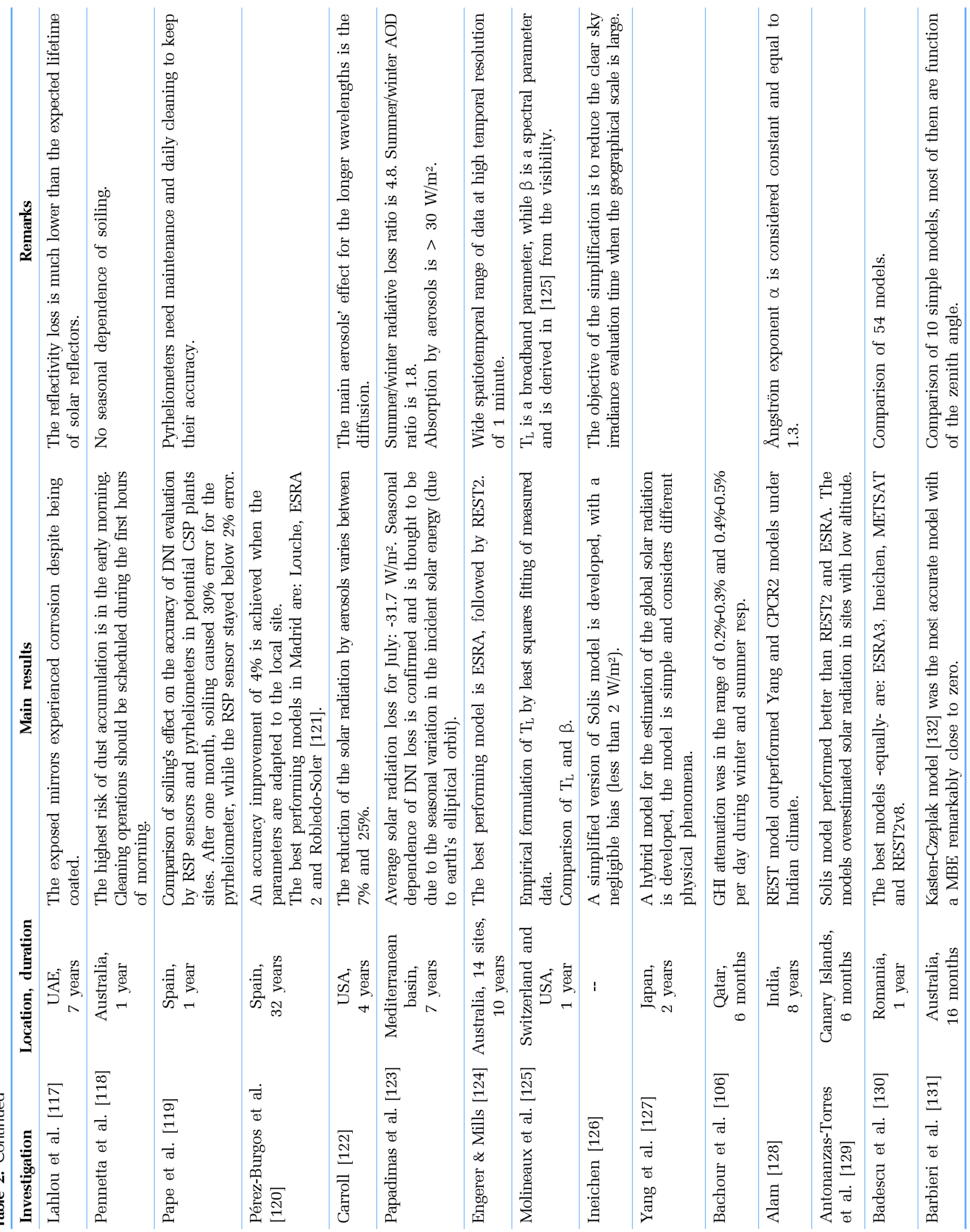




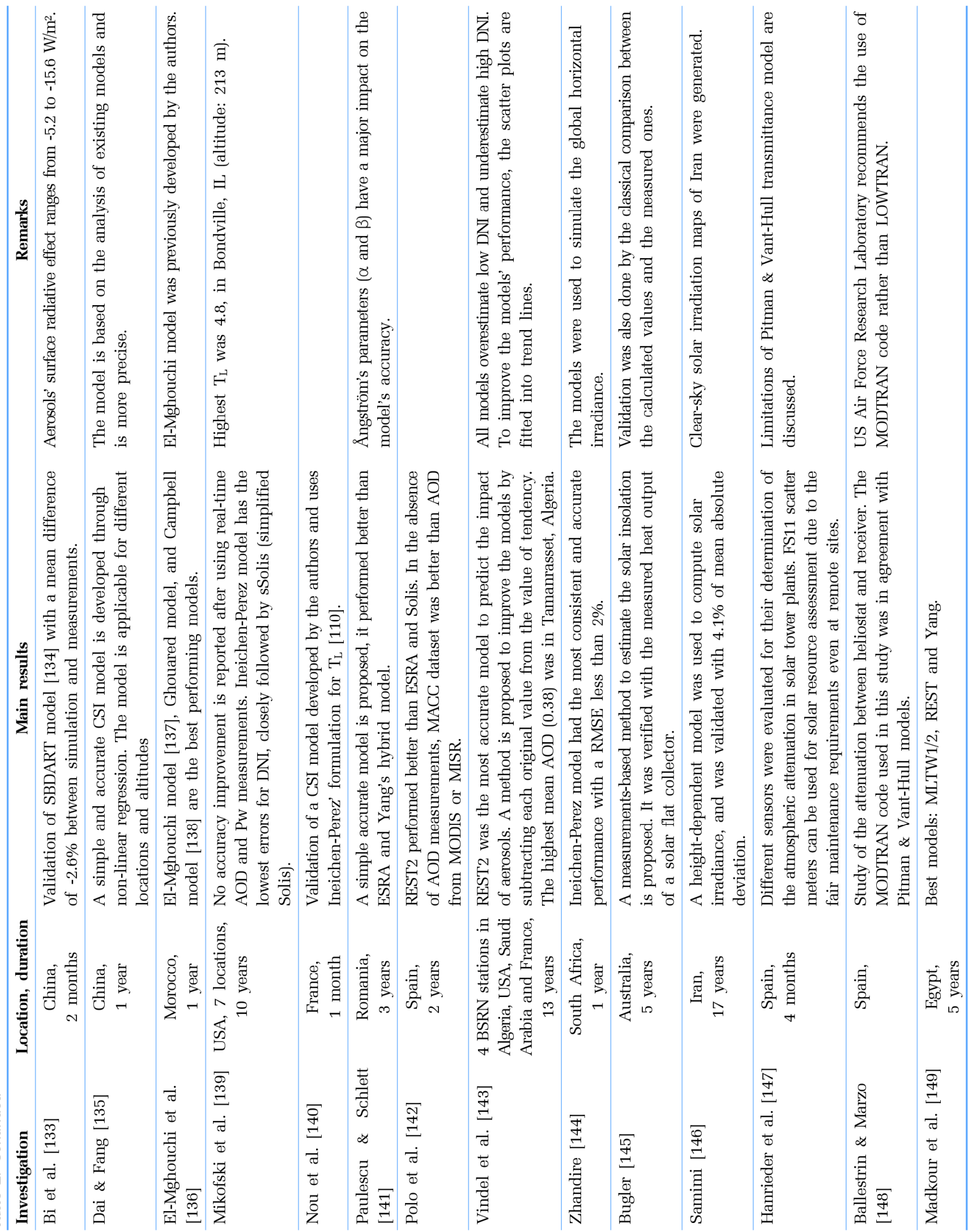


for plant sizing uses DELSOL3 code, which resulted in a $4 \%$ underestimation of the attenuation of irradiance due to aerosols and water vapor, thus, the solar field should be $4 \%$ larger to avoid long term losses. In fact, DELSOL was developed for the specific elevation of Barstow $(0.7 \mathrm{~km})$, CA, USA, corrections should be introduced before applying it to different elevations.

To conclude this section, it is clear from the review of the literature that the radiative effect of aerosols must be accurately evaluated for better long-term exploitation of the solar energy. The performance of the models varies spatially, thus, appropriate corrections should be introduced for better accuracy (as noted by many authors, eg: [38]). The models seem to underestimate high DNI and perform poorly for low solar zenith angles [22, 109], this should be taken into account when developing or applying CSI models to areas with either of the aforementioned climate conditions. Additionally, the complex models are not always more accurate than simple ones (because of the error propagation) [22]. All these factors must be considered to maximize the accuracy of DNI estimation, especially during the planning phase of CSP plants (more similar papers can be found in Table 2). It might also be of interest to rely on next-generation satellites' data, as they can effectively detect the atmospheric disturbances that happen at high altitudes and are not detected from the ground (eg: large TOA dust event reported by [35]), after all, these disturbances cause non-negligible DNI attenuation and can result in considerable losses.

\section{Mitigation Approaches}

\subsection{Washing}

The cleaning of reflectors by rain can be very efficient if it precedes natural adhesive factors, namely high humidity and dew [103]. Niknia et al. [97] studied the impact of cleaning frequencies on the energy yield of a parabolic trough collectors' plant, the extremes of cleaning frequencies were 7 and 42 days, the respective yearly water consumption was 398.9 and $69.0 \mathrm{~m}^{3}$ and the reflectors' efficiency losses were $11 \%$ and $38 \%$; monthly cleaning consumed $99.7 \mathrm{~m}^{3}$ per year and resulted in a yearly efficiency loss of $27 \%$. Periodic cleaning seems to be the most optimal approach according to Ashley et al. [150], who applied a heuristic approach to define the optimal sub-routing for cleaning the field of heliostats. Picotti et al. [151] developed a model to compute economically optimized cleaning schedules in tower plants; the model is based on the physical behavior of soiling and is applied to solar tower plants in Australia and UAE, the results indicate possible up to $15 \%$ gain of the total cleaning cost. Fernández-García et al. [152] tested a variety of washing methods for 2 years under a semi-desert climate, the most effective method was using a brush with demineralized water, the reflectivity was restored to an average of $98.8 \%$; adding detergents to this method did not result in big gains. Bourdon et al. [153] proposed water-saving solutions for CSP plants; first with dust-barriers which stopped $47 \%$ of dust particles larger than $25 \mu \mathrm{m}$. An ultrasonic device (reported to be 4 times more water-economic than the usual cleaning) was used and resulted in a cleanliness factor up to $99 \%$.

\subsection{Electrodynamic Screens "EDS"}

EDS [154, 155] are an emerging method to prevent CSP mirrors' soiling, EDS consist of a transparent dielectric film in which alternated electrodes are deposed; when activated with phased voltage pulses, the electrodynamic field prevents dust particles from depositing on the solar mirror and removes the already deposited particles by charging them, lifting them, and propelling them off the reflector [156, 157]. Stark et al. [158] investigated the efficiency of EDS in preventing CSP mirrors' soiling. Even though EDS application caused an initial reflectivity loss of 3\%, EDS-integrated mirrors kept $>90 \%$ reflectivity without any cleaning operation. Mazumder et al. [159] reported similar experimental results and highlighted the low cost and energy consumption of EDS, namely \$0.005 and $0.2 \mathrm{Wh}$ per $\mathrm{m}^{2}$ per cleaning cycle. After 3 years of study (2017-2020), Mazumder et al. [160] reported that the dust removal efficiency and reflectivity restauration of EDS are both high and that EDS can operate under various temperatures and relative humidity; the authors concluded after an economic analysis that EDS technology is on a commercial level. However, other studies confirmed EDS to be greatly affected by humidity [161, 162], Javed and Guo [163] reported a decreasing dust removal efficiency from $22 \%$ at $\mathrm{RH}$ of $10 \%$ to $9 \%$ at $\mathrm{RH}$ of $80 \%$, and suggested to increase the frequency of EDS device activation (hourly or bi-hourly) in order to improve its cleaning efficiency. Kawamoto [162] recommended to activate the EDS before the ambient temperature gets lower than the dew point at night. While Bernard et al. [164] proposed to coat the EDS with zinc oxide to shield it from the environmental conditions. Further field studies remain necessary to prove the efficiency of this method for CSP plants.

\subsection{Anti-Soiling Coatings}

The idea of using coatings to protect the solar reflectors is more mature than that of using EDS (see for example [165]). Polizos et al. [166] performed durability tests on anti-soiling coatings (spray) composed from multifunctional silica particles and polymeric binders, which are hydrophobic coatings with low surface energy and a high contact angle. The initial reflectivity was higher than $90 \%$, accelerated aging showed that anti-soiling spray could maintain good performances for a period of 18 months to two years. Similar investigations by Hunter et al. [25] reported better results: 99\% of initial solar weighted reflectance, and two to three years of outdoor durability.

While most anti-soiling coatings are hydrophobic, Aranzabe et al. [167] tested a titania-based hydrophilic coating for CSP anti-soiling purposes in Spain for 43 months. Hydrophilic coatings have a high surface energy and a low contact angle, with a totally wet surface being the extreme case. The mirrors that were coated showed a higher average reflectance difference of $3.3 \%$ when compared to the uncoated ones, moreover, the highest reflectance difference was $9.5 \%$. Lorenz et al. [168] studied the economic feasibility of a hydrophilic coating with photo-catalytical functions, a $3 \%$ yearly energy yield gain is expected if the coating is applied.

Wiesinger et al. [169] tested different anti-reflective coatings as an erosion mitigation; the coatings improved the optical performance of the tested glass by around 4.9\%; however, if the CSP site often suffers extreme weather conditions, anti-reflective coatings 
would cause faster optical losses. Even though adding a hydrophobic coating to an anti-reflective one slightly reduced optical performance, it was very effective against sand erosion.

Since 2019, more recent papers report innovative methods of water-saving mitigation by coatings. Wette et al. [170] tested a new hydrophilic coating under real outdoor conditions in PSA for 22 months; the effect of the coating was positive, lower soiling rates and higher cleanliness were observed for the coated mirrors in contrast to the uncoated ones. The optical properties and durability of this coating were studied by Fernández-García et al. [171], the coating did not cause significant change in the initial reflectance (-0.001 \pm 0.003$)$. The durability was assessed via accelerated aging tests and outdoor exposure, the same previous negligible values were observed, which denotes the durability of the anti-soiling coating and its applicability to CSP reflectors. Matal and Naamane [172] conducted accelerated erosion tests of two types of coated solar reflectors: one with a hard coating, the other with an anti-soiling coating; the results suggest that the hard coating is better in terms of optical performance and resistance to mechanical stress. Wette et al. [173] conducted 6 years of outdoor exposure, as well as laboratory abrasion test, to evaluate anti-soiling coatings. One of the tested coatings improved the initial reflectance while the other one did not change it much; this advantageous behavior diminishes for biweekly-cleaned coatings ( 2 years) faster than the monthly-cleaned ones (4 years), which confirms that coatings are water saving. Lopes et al. [174] studied horizontal and tilted coated mirrors in Portugal. The coatings' effect was positive, especially for the tilted samples, while the horizontal ones presented similar soiling rates, coated or not. Pescheux et al. [175] performed extreme accelerated aging tests on different coatings including a commercialized one, the tests simulated severe conditions of salination, humidity, temperature, UV radiations and solar radiation. $\mathrm{SiO}_{2}$ nanoparticles-based hydrophobic coatings performed better than the others, including the commercial one. Sutter et al. [176] studied the impact of dust on tube receivers of the parabolic trough technology for 5 years in Morocco and Spain. Anti-reflective coatings reduced the impact of dust to only -0.014 transmittance loss in Spain, while in Morocco, severe dust events resulted in a transmittance loss of 0.05; accelerated aging tests were also conducted and the highest degradation rate was -0.041 . Wette et al. [177] tested two newly developed anti-soiling coatings during 2 years of exposure in Spain, the coatings were cleaned with pressurized water and a brush; the results suggest that the coatings perform differently and dependently on the cleaning technique: for one type, the pressurized water resulted in a cleanliness gain, for the other type it was vice-versa (poor washability). Yilbas et al. [178] presented recently, in 2021, a comprehensive analysis of dust characterization, soiling mechanisms, and dust mitigation by hydrophobic surfaces for solar energy applications.

\section{Summary}

With the increasing environmental issues caused by greenhouse gases, the transition towards cleaner energy is imperative. One of the most abundant renewable energies is the solar energy, thus its utilization is of prime benefit, especially concentrated solar
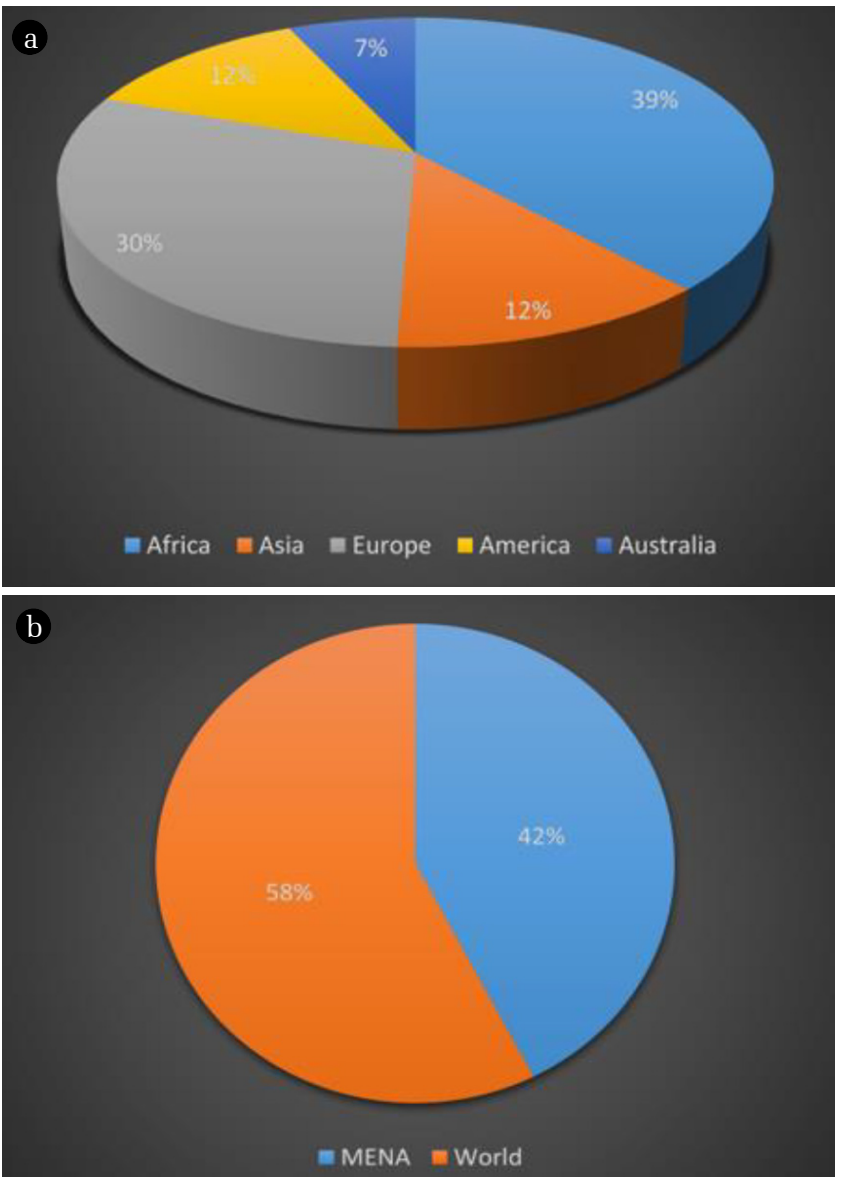

Fig. 6. Studies of soiling problems and mitigation approaches in CSP plants: (a) The repartition of the reviewed studies over the continents. (b) Comparison between the MENA region and the rest of the world.

power (CSP) that is getting increasing interest worldwide. However, the presence of dust in the atmosphere induces an attenuation of the solar energy and a reduction in the efficiency of concentrated solar power (CSP) plants [14, 20]. The globality of this issue is evident by the widespread of the reviewed studies (Fig. 6(a)).

Generally, the regions blessed with high DNI suffer from high aerosols loads, this is especially the case of the MENA region [26, 179, 180], this explains the higher number of the -reviewed- papers studying CSP-related soiling problems in the MENA region (Fig. 6(b)). Soiling is an issue for solar energy applications in general, however, CSP technologies suffer from soiling problems more than PV [51]. The review of the literature shows that no previous review was dedicated to the effect of dust on CSP (unlike PV), and that very few research papers -and no review papers- were interested in both effects of suspended aerosols and deposited dust, or linked turbidity to reflectivity loss (like the studies of [18, 46]), although both effects ought to be simultaneously investigated, since turbid skies accompany the deposition of dust on solar mirrors. Shortage in long term energy production results from the underestimation of both DNI extinction (eg: [38]) and reflectivity loss of the solar field (eg: [50]). Aerosols' attenuation of DNI is reported to be up 
to $25 \%$ [122], and the soiling of solar mirrors causes up to $80 \%$ reflectivity loss [57, 102], while the resulting diminution in energy production can be more than $88 \%$ [107].

Attenuation of the solar energy by aerosols is primarily via scattering more than absorption [41]. The major parameter identifying the attenuation is the Aerosols Optical Depth (AOD) [123], it is found to particularly be the input parameter with crucial impact on CSI models' outputs [83], as well as on extinction models used in solar tower plants [76]. Introducing measured real-time AOD data into models does not improve their accuracy [139]. High AOD values are correlated with low Ångström exponent $\alpha$ [111, 181], thus large aerosols particles result in very hazy atmospheres and are responsible for most of the extinction [18]. The highest measured AOD range from 0.30 (China [133]) to 3.08 (India [111]). To consider the particularities of sites, and since extinction levels in CSP plants are specific to the hosting site [29], it is better to build models for sites with potential for CSP plants (eg: [65, 105]), or introduce the necessary corrections (eg: $[38,120])$. The models underestimate high DNI and perform poorly for low solar zenith angles [22, 109]. The complexity of models is not always an assurance of better performance, sometimes, simple models perform better than complex ones [22], this is because complex models have more error propagation than the simple ones. It might be of interest to depend on data of next-generation satellites, which can detect important atmospheric disturbances that take place at high altitudes and escape ground measurements [35]. The attenuation of solar irradiance by atmospheric aerosols occurs via two optical phenomena: scattering and absorption [37], even though other atmosphere constituents contribute in scattering, most of it is primarily due to aerosols [38]. Theoretically, the optical phenomena happening in the lower atmosphere are best described by the well-known Mie theory [40].

The deposition of dust on solar reflectors is mainly due to gravity more than diffusion [46]. Since AOD is proportional to the soiling rate of solar mirrors [18], monitoring AOD in the surroundings of CSP plants ought to be done, in order to gauge the risk of soiling [46]. Intense, rare soiling events cause much more important reflectivity drops than the frequent, moderate dust deposition [49, 62]. Many authors developed innovative methods to measure soiling rates [71-75, 115]. Soiling of pyrheliometers causes erroneous evaluation of DNI in potential CSP sites [119]. First row mirrors are soiled fast and uniformly, and suffer more dust deposition than the rest of the solar field [53], this should be considered when scheduling cleaning operations. The tilt angle and material of solar reflectors have a crucial impact on the soiling rate: horizontal mirrors are always more soiled than tilted ones, thus, a tilt angle, no matter how slight it is, can reduce the deposition of dust; also, glass mirrors are soiled faster than aluminum ones, and restore their reflectivity faster and better after being washed [36, 46]. Soiling rates can reach high values (eg: $-2.3 \%$ per day [53]), it would be of benefit to keep the factors controlling dust deposition under observation; other than the exposure direction, multiple meteorological factors are directly related to soiling events, namely: wind speed and direction, relative humidity and atmospheric pressure; while high relative humidity values intensify dust deposition, low pressure is associated with rainy days [46, 47]. Monitoring these factors would help program efficient cleaning operations.
Many authors developed and validated soiling models for CSP applications (eg: [65, 69]). The consideration of soiling when modeling the performance of CSP plants resulted in considerable losses of the yielded energy [48]. The weight of the deposited dust can also be used to develop correlations of reflectivity losses [64-67].

Other than the deposition of dust on the reflective surfaces, the optical losses are also caused by the erosion of the solar reflectors, mainly due to sandstorms [60-62]. Erosion intensity varies from site to site, as a result of the variation of particles' shapes that cause different microscopic cracks. The erosion's intensity is affected by the shape of particles more than their hardness [56-58]. The general trend of erosion simulations is to use particles smaller than 250 microns, but larger particles should also be used to avoid erosion underestimation [56].

The primary effect of rain is cleaning the reflecting mirrors more than enhancing their soiling, the latter is mainly due to very light rain $[29,44]$. The highest possibility of soiling is during the early morning, which makes that timing favorable for maximum profit of cleaning operations [118]. Down-facing mirrors remain clean, which makes stowing mobile solar reflectors a good preventive approach [36, 107]. As for materials, the reflectivity of glass mirrors is perfectly restored after cleaning operations [53]. Most mitigation approaches are restorative and water-based, despite the shortage of water in the regions blessed with high DNI. Dry preventive methods include mainly coatings and electrodynamic screens "EDS" [30]. EDS are a water-saving approach. With their high dust removal efficiency and reflectivity restauration, EDS are becoming ready for large-scale use [160]. Coatings of solar mirrors enhance water saving since less cleaning frequencies are required; and the coated reflectors restore their reflectance better than the uncoated ones [173]. Furthermore, the coatings' anti-soiling effect will be more significant when the soiling is more intense [170]. Coatings can be associated with cleaning methods to enhance the optical performance of the reflectors; however, this association of mitigation approaches must be done dependently on the type of coating, different anti-soiling coatings perform differently for cleaning methods, the wrong association can lead to losses in the mirrors' reflectance instead of restoring it [177].

To finalize this section, aerosols and soiling problems still remain in need for further research. The resulted decrease in the solar power plant's overall performance might increase the cost of cleaning operations and therefore increasing the cost of the produced kWh.

The amount and composition of dust -and the consequent lossesrelate to the geography and climate of each region in the world, thus the appropriate mitigation approaches are site-dependent, this explains the recent $\mathrm{R} \& \mathrm{D}$ trend of evaluating experimentally the factors controlling soiling losses in different regions of the world rather than standardizing those losses. The evaluation of the amount of dust is very important to assess the cost of cleaning tasks, and thus assess the viability of CSP projects around the world. The cost of cleaning solar fields must be optimized by adapting the cleaning method to the factors governing the deposition of dust at the plant's site, the careful association of different mitigation approaches can lead to more efficient cleaning operations. The usual scarcity of water in areas with high DNI potential urges the necessity for more research on water-economic solutions. Future 
research should also investigate more the relationship between AOD and reflectivity drop, this can help in the early prediction and prevention of solar mirrors' soiling (by stowing mobile reflectors for example). It is recommended to build site-dependent soiling and extinction models for precise estimation of the optical losses.

\section{Conclusions}

CSP plants suffer production losses due to aerosols-related problems, more than any of the other solar energy technologies; mid-air suspended aerosols result in attenuation of the incident direct normal irradiance, furthermore, the deposition of dust on the reflecting mirrors causes serious reflectivity drops. A literature review of the studies concerned with both DNI attenuation and reflectivity loss is presented, indeed, investigations reported aerosols-related problems to be of serious impact on the production of energy in CSP plants. The main parameters characterizing the atmospheric turbidity are: Aerosols Optical Depth, Linke turbidity factor, and Angström coefficient and exponent. The state of solar mirrors can be expressed through the soiling rate or the cleanliness factor, these parameters are influenced by many factors, mainly tilt angle, wind speed and direction, and relative humidity.

Soiling issues and mitigation strategies still require more research and development. The research, development, and challenges connected to dust issues for CSP plants are examined and summarized in this paper. The review has offered a thorough examination and overview of studies on DNI attenuation and reflectivity losses, as well as the main characteristics of air turbidity, factors of soiling, and mitigation strategies. The following main conclusions can be drawn:

1) Dust and soiling are still issues that need to be addressed. This is particularly true in the world's desert-sand regions, which, ironically, have some of the best solar conditions as well as some of the "best" dust conditions. The lack of natural washing from rain and the small amount of moisture that does fall might result in even more severe soiling.

2) Concentrating solar systems' energy delivery can be considerably reduced when dust is present. Small reductions in a mirror's or heliostat's reflectivity result in significant reductions in CSP performance. Concentrating systems, in general, are more susceptible to dust collection and require greater maintenance in terms of dust mitigation.

3) Mitigation strategies have been discussed including restorative approaches and preventative approaches. Passive methods (which use coatings to prevent dust attachment) and active methods (which actively oppose the charged dust particles) were used as preventative measures. The best mitigation strategy is determined by the geographic location and climate zone. Further research on water-economic mitigation approaches (restorative and preventive approaches) is needed

4) It is best to build site-specific extinction models to consider the particularities of the sites hosting CSP plants.

5) More papers should investigate the relationship between AOD and reflectivity drop, this can lead to the early prediction and even prevention of the reflector's soiling.

\section{Nomenclature}

$\alpha \quad$ Angström turbidity exponent

$\beta \quad$ Angström turbidity coefficient

$\Delta z \quad$ Height difference

$\delta \quad$ Declination angle

$\delta_{c d a}$ Optical thickness of the clear-dry atmosphere

$\lambda$ Wavelength

$V_{d} \quad$ Deposition velocity

$V_{g} \quad$ Free fall velocity

$v_{t} \quad$ Turbulence velocity

$\tau \quad$ Optical Depth

$C_{d} \quad$ Dust concentration

$D \quad$ Particle diameter

d Distance

F Aerosol Forcing

$F_{d} \quad$ Dust deposition flux

$I_{0} \quad$ Normal incident extraterrestrial irradiance

$N_{j} \quad$ Julian day number

$n \quad$ Refraction index

$P \quad$ Pressure

$r_{a} \quad$ Aerodynamic resistance

$r_{b} \quad$ Brownian diffusion resistance

SfC Surface level

$T_{L} \quad$ Linke's turbidity factor

$X \quad$ Extinction coefficient

Z Solar Zenith Angle

\section{Author Contributions}

K.Z. (Ph.D student) collected data and wrote the manuscript. A.G. (Assistant Professor) supervised, wrote sections 4 and 6 and revised the manuscript. M.A. (Professor) supervised and wrote sections 4 and 6. N.R. (Ph.D) wrote sections 1-3, 7, 8. F.Y. (Assistant Professor) wrote sections 1-3, 7, 8. N.L.P. (Assistant Professor) wrote section 5 , revised the manuscript and checked the language.

\section{References}

1. Satheesh SK, Krishna Moorthy K. Radiative effects of natural aerosols: A review. Atmos. Environ. 2005;39:2089-2110.

2. Wen L, Ma Z, Li Y, Li Q. An investigation and forecast on $\mathrm{CO}_{2}$ emission of China: Case studies of Beijing and Tianjin Environ. Eng. Res. 2017;22:407-416.

3. Kong Y, He W. The path analysis of carbon emission reduction: A case study of the Silk Road Economic Belt. Environ. Eng. Res. 2020;25:71-79.

4. Vakulchuk R, Overland I, Scholten D. Renewable energy and geopolitics: A review. Renew. Sustain. Energy Rev. 2020;122: 109547.

5. McGlade C, Ekins P. The geographical distribution of fossil fuels unused when limiting global warming to $2{ }^{\circ} \mathrm{C}$. Nature 2015;517:187-190.

6. Sun W, Sun J. Prediction of carbon dioxide emissions based 
on principal component analysis with regularized extreme learning machine: The case of China. Environ. Eng. Res. 2017;22:302-311.

7. Aouadj S, Zebirate S, Smail R, Saidi F. Optimization of the technical and environmental performance of the renewable energies. Case of the hybrid powerplant 'SPPI' of HassiR'mel in the central highlands of Algeria. Environ. Eng. Res. 2021;26:200056.

8. Syahira FKA, Umi FMA, Khairuddin MI. Compilation of liquefaction and pyrolysis method used for bio-oil production from various biomass: A review. Environ. Eng. Res. 2020;25:18-28.

9. Hamayun MH, Hussain M, Shafiq I, Ahmed A, Park YK. Investigation of the thermodynamic performance of an existing steam power plant via energy and exergy analyses to restrain the environmental repercussions: A simulation study. Environ. Eng. Res. 2022;27:200683.

10. Yettou F, Azoui B, Malek A, Gama A, Panwar NL. Solar cooker realizations in actual use: An overview Renew. Sustain. Energy Rev. 2014;37:288-306.

11. Kazem HA, Chaichan MT, Al-Waeli A, Sopian K. A review of dust accumulation and cleaning methods for solar photovoltaic systems. J. Clean. Prod. 2020;276:123187.

12. Behar O, Khellaf A, Mohammedi K. A review of studies on central receiver solar thermal power plants. Renew. Sustain. Energy Rev. 2013;23:12-39.

13. López G, Gueymard CA, Bosch JL, et al. Modeling water vapor impacts on the solar irradiance reaching the receiver of a solar tower plant by means of artificial neural networks. Sol. Energy 2018;169:34-39.

14. Rathore N, Panwar NL, Yettou F, Gama A. A Comprehensive review on different types of solar photovoltaic cells and their applications. Int. J. Ambient Energy 2019;42(10):1-48.

15. Kazem HA, Chaichan MT, Al-Waeli A, Sopian K. A novel model and experimental validation of dust impact on grid-connected photovoltaic system performance in Northern Oman. Sol. Energy 2020;206:564-578.

16. Kazem HA, Chaichan MT. Experimental analysis of the effect of dust's physical properties on photovoltaic modules in Northern Oman. Sol. Energy 2016;139:68-80.

17. Chaichan MT, Kazem HA, Ibrahim SI, Radhi AA, Mahmoud BK, Ali AJ. Photovoltaic panel type influence on the performance degradation due dust accumulation. IOP Conf. Ser.: Mater. Sci. Eng. 2020;928:022092.

18. Raillani B, Ouali HAL, Amraqui S, Moussaoui MA, Jeyar M, Mezrhab A. The Impact of Aerosol Optical Depth (AOD) On Decreasing the Optical Efficiency of CSP Solar Power Plants-A case study Eastern Morocco. In: 2019 International Conference on Intelligent Systems and Advanced Computing Sciences (ISACS); 26-27 December 2019; Taza, Morocco. p. 1-4.

19. Khalil SA, Shaffie AM. Attenuation of the solar energy by aerosol particles: A review and case study. Renew. Sustain. Energy Rev. 2016;54:363-375.

20. Yadav NK, Pala D, Chandra L. On the understanding and analyses of dust deposition on heliostat. Energy Procedia 2014;57:3004-3013.

21. Sarver T, Al-Qaraghuli A, Kazmerski LL. A comprehensive review of the impact of dust on the use of solar energy: History, investigations, results, literature, and mitigation approaches. Renew. Sustain. Energy Rev. 2013;22:698-733.

22. Ruiz-Arias JA, Gueymard CA. Worldwide inter-comparison of clear-sky solar radiation models: Consensusbased review of direct and global irradiance components simulated at the earth surface. Sol. Energy 2018;168:10-29.

23. Diagne M, David M, Lauret P, Boland J, Schmutz N. Review of solar irradiance forecasting methods and a proposition for small-scale insular grids. Renew. Sustain. Energy Rev. 2013;27:65-76.

24. Sengupta M, Wagner M. Atmospheric attenuation in central receiver systems from DNI measurements. In: the World Renewable Energy Forum, 13-17 May 2012; Denver, Colorado.

25. Hunter SR, Smith DB, Polizos G, Schaeffer DA, Lee DF, Datskos PG. Low cost anti-soiling coatings for CSP collector mirrors and heliostats. In: Plesniak AP, Pfefferkorn eds. High and Low Concentrator Systems for Solar Energy Applications IX, 91750J. SPIE Solar Energy + Technology, 17-21 August 2014; San Diego, California.

26. Ghazi S, Sayigh A, Ip K. Dust effect on flat surfaces - A review paper. Renew. Sustain. Energy Rev. 2014;33:742-751.

27. Costa SCS, Diniz ASAC, Kazmerski LL. Dust and soiling issues and impacts relating to Solar Energy systems: Literature review update for 2012-2015. Renew. Sustain. Energy Rev. 2016;63:33-61.

28. Costa SCS, Diniz ASAC, Kazmerski LL. Solar Energy dust and soiling R\&D progress: Literature review update for 2016. Renew. Sustain. Energy Rev. 2018;82:2504-2536.

29. Hanrieder N, Wilbert S, Mancera-Guevara D, Buck R, Giuliano S, Pitz-Paal R. Atmospheric extinction in solar tower plants - A review. Sol. Energy 2017;152:193-207.

30. Bouaddi S, Fernández-García A, Sansom C, et al. A Review of Conventional and Innovative-Sustainable Methods for Cleaning Reflectors in Concentrating Solar Power Plants. Sustainability 2018;10:3937.

31. Antonanzas-Torres F, Urraca R, Polo J, Perpiñán-Lamigueiro O, Escobar R. Clear sky solar irradiance models: A review of seventy models. Renew. Sustain. Energy Rev. 2019;107:374-387.

32. Pöschl U. Atmospheric Aerosols: Composition, Transformation, Climate and Health Effects. Angew. Chem. Int. Ed. 2005;44:7520-7540.

33. Cai Q, Tong L, Zhang J, et al. Characteristics of long-range transported PM2.5 at a coastal city using the single particle aerosol mass spectrometry. Environ. Eng. Res. 2019;24:690-698.

34. Elminir HK, Ghitas AE, Hamid RH, El-Hussainy F, Beheary MM, Abdel-Moneim KM. Effect of dust on the transparent cover of solar collectors. Energy Convers. Manag. 2006;47:3192-3203.

35. Goto D, Kikuchi M, Suzuki K, et al. Aerosol model evaluation using two geostationary satellites over East Asia in May 2016. Atmos. Res. 2019;217:93-113.

36. Alami Merrouni A, Wolfertstetter F, Mezrhab A, Wilbert S, Pitz-Paal R. Investigation of soiling effect on different solar mirror materials under Moroccan climate. Energy Procedia 2015;69:1948-1957.

37. Iqbal M. An introduction to solar radiation. $1^{\text {st }}$ ed. Elsevier: Academic Press; 1983.

38. Cardemil JM, Starke AR, Scariot VK, Grams IL, Colle S. 
Evaluating solar radiation attenuation models to assess the effects of climate and geographical location on the heliostat field efficiency in Brazil. Energy Procedia 2014;49:1288-1297.

39. Rathore N, Panwar NL, Gama A, Yettou F. Solar map of India under clear sky conditions. Int. J. Sustain. Energy 2019;38:415-446.

40. Haywood JM, Francis PN, Glew MD, Taylor JP. Optical properties and direct radiative effect of Saharan dust: A case study of two Saharan dust outbreaks using aircraft data. J. Geophys. Res. 2001;106:18417-18430.

41. Pettit RB, Freese JM. Wavelength dependent scattering caused by dust accumulation on solar mirrors. Sol. Energy Mater. 1980;3:1-20.

42. Gilligan JE, Brzuskiewicz J. Outdoor testing of Solar Energy utilization materials. In: Proceedings of Institute of Environmental Sciences; 1976. p. 303.

43. Figgis B, Ennaoui A, Guo B, Javed W, Chen S. Outdoor soiling microscope for measuring particle deposition and resuspension. Sol. Energy 2016;137:158-164.

44. Picotti G, Borghesani P, Manzolini G, Cholette ME, Wang R. Development and experimental validation of a physical model for the soiling of mirrors for CSP industry applications. Sol. Energy 2018;173:1287-1305.

45. Berg RS. Heliostat dust buildup and cleaning studies. Sandia laboratory, Report $N^{\circ}$ SAND78-0510. Sandia National Laboratories, Albuquerque, New Mexico 87185 and Livermore, California 94550. US; 1978.

46. Griffith DJ, Vhengani L, Maliage M. Measurements of mirror soiling at a candidate CSP site. Energy Procedia 2014;49:1371-1378.

47. Fuji M, Machida K, Takei T, Watanabe T, Chikazawa M. Effect of Wettability on Adhesion Force between Silica Particles Evaluated by Atomic Force Microscopy Measurement as a Function of Relative Humidity. Langmuir 1999;15:4584-4589.

48. Alami Merrouni A, Conceição R, Mouaky A, Silva HG, Ghennioui A. CSP performance and yield analysis including soiling measurements for Morocco and Portugal. Renew. Energy 2020;162:1777-1792.

49. Conceição R, Merrouni AA, Lopes D, et al. A comparative study of soiling on solar mirrors in Portugal and Morocco Preliminary results for the dry season. AIP Conf. Proc. 2019;2126:220001.

50. Azouzoute A, Merrouni AA, Garoum M, Bennouna EG, Ghennioui A, El-Ydrissi M. The impact of optical soiling losses on the electrical production of CSP power plant. AIP Conf. Proc. 2019;2123:020090.

51. Hachicha AA, Al-Sawafta IDB. Hamadou DB. Numerical and experimental investigations of dust effect on CSP performance under United Arab Emirates weather conditions. Renew. Energy 2019;143:263-276.

52. Bellmann P, Wolfertstetter F, Conceição R, Silva HG. Comparative modeling of optical soiling losses for CSP and PV energy systems. Sol. Energy 2020;197:229-237.

53. Bouaddi S, Ihlal A, Fernández-García A. Comparative analysis of soiling of CSP mirror materials in arid zones. Renew. Energy 2017;101:437-449.

54. Wiesinger F, Sutter F, Wolfertstetter F, et al. Sandstorm erosion simulation on solar mirrors and comparison with field data.
AIP Conf. Proc. 2017;1850:130014.

55. Azouzoute A, Merrouni AA, Garoum M, Bennouna EG. Comparison of soiling effect of two different solar mirrors in mid-south of Morocco. AIP Conf. Proc. 2019;2126:190002.

56. Sansom C, Almond H, King P, Endaya E, Bouaichaoui S. Airborne sand and dust soiling of solar collecting mirrors. AIP Conf. Proc. 2017;1850:130011.

57. Guerguer M, Karim M, Naamane S, Edfouf Z, Raccurt O, Delord C. Soiling deposition on solar mirrors exposed in Morocco. AIP Conf. Proc. 2017;1850:130005.

58. Endaya E, Sansom C, Comley P, Almond H, Dekam EI, Abdunnabi MJR. Simulation of The Effect of Libyan Sand on The Reflectance Surface of CSP. Sol. Energy Sustain. Dev. 2019;8:33-46.

59. Wiesinger F, Sutter F, Fernández-García A, et al. Sandstorm erosion on solar reflectors: Highly realistic modeling of artificial aging tests based on advanced site assessment. Appl. Energy 2020;268:114925.

60. Wiesinger F, Sutter F, Wolfertstetter F, et al. Assessment of the erosion risk of sandstorms on solar energy technology at two sites in Morocco. Sol. Energy 2018;162:217-228.

61. Matal A, Karim M, Naamane S. Development and calibration of an experimental test bench simulating solar reflectors erosion. Sol. Energy 2020;201:724-731.

62. Wiesinger F, Sutter F, Fernández-García A, Wette J, Hanrieder N. Sandstorm erosion on solar reflectors: A field study on height and orientation dependence. Energy 2021;217:119351.

63. Buendía-Martínez F, Sutter F, Wette J, Valenzuela L, Fernández-García A. Lifetime prediction model of reflector materials for concentrating solar thermal energies in corrosive environments. Sol. Energy Mater. Solar Cells 2021;224:110996.

64. Zhao X, Chen Z, Yan S, Ming T, Wu Z, Ma R. Influence of Dust Accumulation on the Solar Reflectivity of a Linear Fresnel Reflector. J. Therm. Sci. 2020;30(5):1526-1540.

65. Wu Z, Yan S, Wang Z, et al. The effect of dust accumulation on the cleanliness factor of a parabolic trough solar concentrator. Renew. Energy 2020;152:529-539.

66. Azouzoute A, Merrouni AA, Garoum M. Soiling loss of solar glass and mirror samples in the region with arid climate. Energy Rep. 2020;6:693-698.

67. Usamentiaga R, Fernández-García A, Carús JL. Evaluation of Dust Deposition on Parabolic Trough Collectors in the Visible and Infrared Spectrum. Sensors 2020;20:6249.

68. Heimsath A, Nitz P. The effect of soiling on the reflectance of solar reflector materials - Model for prediction of incidence angle dependent reflectance and attenuation due to dust deposition. Sol. Energy Mater. Solar Cells 2019;195:258-268.

69. Heimsath A, Sutardhio C, Schöttl P, Nitz P. Soiling of solar mirrors-impact of incidence angles on CSP plant performance. AIP Conf. Proc. 2020;2303:210003.

70. Vicente GS, German N, Maccari A, Fernández-García A, Morales A. Soiling study on antireflective coated glass samples and antisoiling antireflective coated glass samples. AIP Conf. Proc. 2020;2303:210005.

71. Wolfertstetter F, Wilbert S, Bellmann P, et al. T-TraCS - An automated method to measure soiling losses at parabolic trough receiver tubes. AIP Conf. Proc. 2020;2303:210006. 
72. Guerguer M, Naamane S, Raccurt O, Bouaouine H. Neural network modeling of Moroccan weather conditions effect on solar reflectors degradation. AIP Conf. Proc. 2020;2303:150008.

73. Le-Baron E, Grosjean A, Bourdon D, Pescheux AC, Vidal F, Disdier A. New equipment for measurement of soiling and specular reflectance on solar mirrors. AIP Conf. Proc. 2020;2303:150011.

74. Wolfertstetter F, Hanrieder N, Bellmann F, Ghennioui A, Wette J, Fernández-García A. Parallel soiling measurements for 4 mirror samples during outdoor exposure with TraCS. AIP Conf. Proc. 2020;2303:100009.

75. Wolfertstetter F, Fonk R, Prahl C, Röger M, Wilbert S, Fernández-Reche J. Airborne soiling measurements of entire solar fields with Qfly. AIP Conf. Proc. 2020;2303:100008.

76. Polo J, Ballestrin J, Carra E. Assessment and improvement of modeling the atmospheric attenuation based on aerosol optical depth information with applicability to solar tower plants. Energy 2020;208:118399.

77. Polo J, Ballestrin J, Carra E. Sensitivity study for modelling atmospheric attenuation of solar radiation with radiative transfer models and the impact in solar tower plant production. Sol. Energy 2016;134:219-227.

78. Carra E, Marzo A, Ballestrin J, et al. Atmospheric extinction levels of solar radiation using aerosol optical thickness satellite data. Validation methodology with measurement system. Renew. Energy 2020;149:1120-1132.

79. Hanrieder N, Ghennioui A, Merrouni AA, et al. Atmospheric Transmittance Model Validation for CSP Tower Plants. Remote Sens. 2019;11:1083.

80. Hanrieder N, Sengupta M, Xie Y, Wilbert S, Pitz-Paal R. Modeling beam attenuation in solar tower plants using common DNI measurements. Sol. Energy 2016;129:244-255.

81. Amiridis V, Marinou E, Tsekeri A, et al. LIVAS: a 3-D multi-wavelength aerosol/cloud database based on CALIPSO and EARLINET. Atmos. Chem. Phys. 2015;15:2247-2304.

82. Berrisford P, Dee D, Poli P, et al. The ERA-Interim archive Version 2.0, Shinfield Park. Reading 2011;1:23.

83. Benkaciali S, Haddadi M, Khellaf A. Evaluation of direct solar irradiance from 18 broadband parametric models: Case of Algeria. Renew. Energy 2018;125:694-711.

84. Grosjean A, Le-Baron E, Pescheux AC, Disdier A. Long time series solar spectra used for solar field performance evaluation. AIP Conf. Proc. 2020;2303:180001.

85. Gueymard CA, Myers D, Emery K. Proposed reference irradiance spectra for solar energy systems testing. Sol. Energy 2002;73:443-467.

86. Bright JM, Gueymard CA. Climate-specific and global validation of MODIS Aqua and Terra aerosol optical depth at 452 AERONET stations. Sol. Energy 2019;181:594-605.

87. Behar O, Sbarbaro D, Moran L. A simplified methodology to estimate solar irradiance and atmospheric turbidity from ambient temperature and relative humidity. Renew. Sustain. Energy Rev. 2019;116:109310.

88. Marif Y, Bechki D, Zerrouki M, Belhadj MM, Bouguettaia H, Benmoussa H. Estimation of atmospheric turbidity over Adrar city in Algeria. J. King Saud Univ. Sci. 2019;31:143-149.

89. Capderou M. Modèles Théoriques et Expérimentaux. In: Atlas
Solaire de l'Algérie(volumes 1, parts 1-2). Alger: Office des publications universitaires; 1987. p. 375.

90. Badescu V, Gueymard CA, Cheval S, et al. Computing Global and Diffuse Solar Hourly Irradiation on Clear Sky: Review and Testing of 54 Models. Renew. Sustain. Energy Rev. 2012;16:1636-1656.

91. Yu L, Zhang M, Wang L, Lu Y, Li J. Effects of aerosols and water vapour on spatial-temporal variations of the clear-sky surface solar radiation in China. Atmos. Res. 2021;248:105162.

92. Abreu EFM, Canhoto P, Costa MJ. Development of a clear-sky model to determine circumsolar irradiance using widely available solar radiation data. Sol. Energy 2020;205:88-101.

93. Yang D. Choice of clear-sky model in solar forecasting. J. Renew. Sustain. Energy 2020;12:026101.

94. Bright JM, Sun X, Gueymard CA, Acord B, Wang P, Engerer NA. Bright-Sun A globally applicable 1-min irradiance clear-sky detection model. Renew. Sustain. Energy Rev. 2020;121:109706.

95. Bright JM, Bai X, Zhang Y, Sun X, Acord B, Wang P. irradpy Python package for MERRA2 download, extraction and usage for clear-sky irradiance modelling. Sol. Energy 2020;199:685-693.

96. Singh G, Saini D, Sarma R, et al. Dust deposition mechanism and cleaning strategy for open volumetric air receiver based solar tower sub-systems. Energy Procedia 2015;69:2081-2089.

97. Niknia I, Yaghoubi M, Hessani R. A novel experimental method to find dust deposition effect on the performance of parabolic trough solar collectors. Int. J. Environ. Stud. 2012;69:233-252.

98. Karim M, Naamane S, Delord C, Bennouna A. Study of the surface damage of glass reflectors used in Concentrated Solar Power Plants. Energy Procedia 2015;69:106-115.

99. Bouaddi S, Ihlal A. Monthly soiling comparison of CSP candidate mirrors exposed in southwest Morocco. Mater. Today 2016;3:2556-2561.

100. Karim M, Naamane S, Delord C, Bennouna A. Laboratory simulation of the surface erosion of solar glass mirrors. Sol. Energy 2015;118:520-532.

101. Wiesinger F, Sutter F, Fernández-García A, Reinhold J, Pitz-Paal R. Sand erosion on solar reflectors: Accelerated simulation and comparison with field data. Sol. Energy Mater. Solar Cells 2016;145:303-313.

102. Bouaddi S, Ihlal A, Fernández-García A. Soiled CSP solar reflectors modeling using dynamic linear models. Sol. Energy 2015;122:847-863.

103. Guan Z, Yu S, Hooman K, Gurgensi H, Barry J. Dust characterisation for solar collector deposition and cleaning in a concentrating solar thermal power plant. In: Proceedings of International Conference on Heat Exchanger Fouling and Cleaning; 7-12 June 2015; Dublin, Ireland.

104. Sansom C, Comley P, King P, Almond H, Atkinson C, Endaya E. Predicting the effects of sand erosion on collector surfaces in CSP plants. Energy Procedia 2015;69:198-207.

105. Deffenbaugh DM, Green ST, Svedeman SJ. The effect of dust accumulation on line-focus parabolic trough solar collector performance. Sol. Energy 1986;36:139-146.

106. Bachour D, Perez-Astudillo D, Martin-Pomares L. Study of soiling on pyranometers in desert conditions. In: 11th ISES EUROSUN 2016 conference; 12-14 October 2016; Palma de 
Mallorca, Spain.

107. Boyle L, Flinchpaugh H, Hannigan M. Assessment of PM Dry Deposition on Solar Energy Harvesting Systems: Measurement - Model Comparison. Aerosol. Sci. Technol. 2016;50:380-391.

108. Pennetta S, Yu S, Cholette M, Barry J, Guan Z. An investigation on factors influencing dust accumulation on CSP mirrors. AIP Conf. Proc. 2016;1734:070024.

109. Ineichen P. Validation of models that estimate the clear sky global and beam solar irradiance. Sol. Energy 2016;132:332-344.

110. Ineichen P, Perez R. A new air mass independent formulation for the Linke turbidity coefficient. Sol. Energy 2002;73:151-157.

111. Singh S, Nath S, Kohli R, Singh R. Aerosols over Delhi during pre-monsoon months: Characteristics and effects on surface radiation forcing. Geophys. Res. Lett. 2005;32:L13808.

112. Bilbao J, Román R, Yousif C, Mateos D, de Miguel A. Total Ozone column, water vapour and aerosol effects on erythemal and global solar irradiance in Marsaxlokk, Malta. Atmos. Environ. 2014;99:508-518.

113. Tahboub Z, Oumbe A, Hassar Z, Obaidli A. Modeling of irradiance attenuation from a heliostat to the receiver of a solar central tower. Energy Procedia 2014;49:2405-2413.

114. Zhang L, Gong S, Padro J, Barrie L. A size-segregated particle dry deposition scheme for an atmospheric aerosol module. Atmos. Environ. 2001;35:549-560.

115. Wolfertstetter F, Pottler K, Merrouni AA, Mezrhab A, Pitz-Paal R. A Novel Method for Automatic Real-Time Monitoring of Mirror Soiling Rates. In: 18th SolarPACES Conference; 11-14 September 2012; Marrakech; Morocco.

116. Delord C, Blaise A, Fernández-García A, Martínez-Arcos L, Sutter F, Reche-Navarro TJ. Soiling and degradation analysis of solar mirrors. AIP Conf. Proc. 2016;1734:090001.

117. Lahlou R, Al-Naimi K, Al-Yammahi H, et al. Study and comparison of naturally-aged and As-received silvered-glass reflectors. AIP Conf. Proc. 2018;2033:230007.

118. Pennetta S, Anglani F, Barry J, Yu S. A Case Study on Parameters Influencing Dust Accumulation on CSP Reflectors. J. Energy Power Eng. 2016;10:73-81.

119. Pape B, Batlles J, Geuder N, Piñero RZ, Adan F, Pulvermueller B. Soiling impact and correction formulas in solar measurements for CSP projects. In: $15^{\text {th }}$ SolarPACES Conference; $15-18$ September 2009; Berlin.

120. Pérez-Burgos A, Díez-Mediavilla M, Alonso-Tristán C, Rodríguez-Amigo M. Analysis of solar direct irradiance models under clear-skies: evaluation of the improvements for locally adapted models. J. Renew. Sustain. Energy 2017;9:023703.

121. Robledo L, Soler A. Luminous efficacy of direct solar radiation for clear skies. Energy 2000;25:689-701.

122. Carroll JJ. Effects of stratospheric aerosol on measured shortwave radiation incident at the ground. J. Geophys. Res. 1984;89:2553-2561.

123. Papadimas CD, Hatzianastassiou N, Matsoukas C, Kanakidou M, Mihalopoulos N, Vardavas I. The direct effect of aerosols on solar radiation over the broader Mediterranean basin. Atmos. Chem. Phys. 2012;12:7165-7185.
124. Engerer NA, Mills FP. Validating nine clear sky radiation models in Australia. Sol. Energy 2015;120:9-24.

125. Molineaux B, Ineichen P, Delaunay JJ. Direct luminous efficacy and atmospheric turbidity improving model performance. Sol. Energy 1995;55:125-137.

126. Ineichen P. A broadband simplified version of the Solis clear sky model. Sol. Energy 2008;82:758-762.

127. Yang K, Hwang GW, Tamai N. A hybrid model for estimating global solar radiation. Sol. Energy 2001;70:13-22.

128. Alam S. Prediction of direct and global solar irradiance using broadband models: Validation of REST model. Renew. Energy 2006;31:1253-1263.

129. Antonanzas-Torres F, Antonanzas J, Urraca R, Alia-Martinez M, Martinez-de-Pison FJ. Impact of atmospheric components on solar clear-sky models at different elevation: Case study Canary Islands. Energy Convers. Manag. 2016;109:122-129.

130. Badescu V, Gueymard CA, Cheval S, et al. Accuracy analysis for fifty-four clear-sky solar radiation models using routine hourly global irradiance measurements in Romania. Renew. Energy 2013;55:85-103.

131. Barbieri F, Rifflart C, Vo BT, Rajakaruna S, Ghosh A. A comparative study of clear-sky irradiance models for Western Australia. In: IEEE Power and Energy Society General Meeting (PESGM); 2016.

132. Kasten F, Czeplak G. Solar and terrestrial radiation dependent on the amount and type of cloud. Sol. Energy 1980;24:177-189.

133. Bi J, Huang J, Fu Q, et al. Field measurement of clear-sky solar irradiance in Badain Jaran Desert of Northwestern China. J. Quant. Spectrosc. Radiat. Transf. 2013;122:194-207.

134. Ricchiazzi P, Yang S, Gautier C, Sowle D. SBDART: A research and teaching software tool for plane-parallel radiative transfer in the Earth's atmosphere. Bull. Am. Meteorol. Soc. 1998;79:2101-2114.

135. Dai Q, Fang X. A simple model to predict solar radiation under clear sky conditions. Adv. Space Res. 2014;53:1239-1245.

136. El Mghouchi Y, Ajzoul T, Taoukil D, El-Bouardi A. The most suitable prediction model of the solar intensity, on horizontal plane, at various weather conditions in a specified location in Morocco. Renew. Sustain. Energy Rev. 2016;54:84-98.

137. El Mghouchi Y, El Bouardi A, Choulli Z, Ajzoul T. New model to estimate and evaluate the solar radiation. Int. J. Sustain. Built Environ. 2014;3:225-234.

138. Campbell GS, Norman JM. An introduction to environmental biophysics. 2nd ed. New York: Springer; 2012.

139. Mikofski MM, Hansen CW, Holmgren WF, Kimball GM. Use of measured aerosol optical depth and precipitable water to model clear sky irradiance. In: 2017 IEEE 44th Photovoltaic Specialist Conference (PVSC); 25-30 June 2017; Washington, DC.

140. Nou J, Chauvin R, Thil S, Eynard J, Grieu S. Clear-sky irradiance model for real-time sky imager application. Energy Procedia 2015;69:1999-2008.

141. Paulescu M, Schlett Z. A simplified but accurate spectral solar irradiance model. Theor. Appl. Climatol. 2003;75:203212.

142. Polo J, Antonanzas-Torres F, Vindel JM, Ramirez L. Sensitivity 
of satellite based methods for deriving solar radiation to different choice of aerosol input and models. Renew. Energy 2014;68:785-792.

143. Vindel JM, Polo J, Antonanzas-Torres F. Improving daily output of global to direct solar irradiance models with ground measurements. J. Renew. Sustain. Energy 2013;5:063123.

144. Zhandire E. Predicting clear-sky global horizontal irradiance at eight locations in South Africa using four models. J. Energy South. Africa 2017;28(4):77-86.

145. Bugler JW. The determination of hourly insolation on an inclined plane using a diffuse irradiance model based on hourly measured global horizontal insolation. Sol. Energy 1977;19:477-491.

146. Samimi J. Estimation of height-dependent solar irradiation and application to the solar climate of Iran. Sol. Energy 1994;52:401-409.

147. Hanrieder N, Wehringer F, Wilbert S, et al. Determination of beam attenuation in tower plants. In: $18^{\text {th }}$ SolarPACES Conference; 11-14 September 2012; Marrakech, Morocco.

148. Ballestrin J, Marzo A. Solar Radiation Attenuation in Solar Tower Plants. Sol. Energy 2012;86:388-392.

149. Madkour MA, El-Metwally M, Hamed AB. Comparative study on different models for estimation of direct normal irradiance (DNI) over Egypt atmosphere. Renew. Energy 2006;31:361-382.

150. Ashley T, Carrizosa E, Fernández-Cara E. Heliostat field cleaning scheduling for Solar Power Tower plants A heuristic approach. Appl. Energy 2019;235:653-660.

151. Picotti G, Moretti L, Cholette ME, et al. Optimization of cleaning strategies for heliostat fields in solar tower plants. Sol. Energy 2020;204:501-514.

152. Fernández-García A, Álvarez-Rodrigo L, Martínez-Arcos L, Aguiar R, Márquez-Payés JM. Study of Different Cleaning Methods for Solar Reflectors Used in CSP Plants. Energy Procedia 2014;49:80-89.

153. Bourdon D, Wolfertstetter F, Fernández-García A, et al. Saving water on concentrated solar power plants: The holistic approach of the WASCOP project. AIP Conf. Proc. 2020;2303: 210002.

154. Mazumder MK, Sims RA, Wilson JD. Transparent self-cleaning dust shield. 2005; Patent $\mathrm{N}^{\circ}$ US 6,911,593 B2.

155. Sayyah A, Horenstein M, Mazumder M. Mitigation of soiling losses in concentrating solar collectors. In: Conference Record of the IEEE Photovoltaic Specialists Conference; 16-21 June 2013; Florida.

156. Mazumder M, Horenstein M, Stark J, et al. Development of self-cleaning solar collectors for minimizing energy yield loss caused by dust deposition. In: ASME 2013 7th International Conference on Energy Sustainability; 14-19 July 2013; Minneapolis, USA.

157. Mazumder M, Yellowhair J, Stark J, et al. Optical and adhesive properties of dust deposits on solar mirrors and their effects on specular reflectivity and electrodynamic cleaning for mitigating energy-yield loss. In: SPIE 9175, High and Low Concentrator Systems for Sol. Energy Applications IX, 91750K; 17-21 August 2014; California.

158. Stark J, Yellowhair J, Hudelson J, Horenstein M, Mazumder M. Optical Modeling of Reflectivity Loss Caused by Dust
Deposition on CSP Mirrors and Restoration of Energy Yield by Electrodynamic Dust Removal. In: Proceedings of the ASME 2014 8th International Conference on Energy Sustainability; 30 June - 2 July 2014; Boston, Massachusetts.

159. Mazumder M, Ellinger C, O'Connor K, et al. Industrial Production and Field Evaluation of Transparent Electrodynamic Screen (EDS) Film for Water-Free Cleaning of Solar Collectors. In: 2019 IEEE 46th Photovoltaic Specialists Conference (PVSC); 16-21 June 2019; Chicago, USA.

160. Mazumder M, Horenstein M, Joglekar N, et al. Enhancement of Optical Efficiency of CSP Mirrors for Reducing O\&M Cost via Near-Continuous Operation of Self-Cleaning Electrodynamic Screens (EDS). Boston University Award \# DE-EE0007119. U.S. Department of Energy Office of Energy Efficiency and Renewable Energy NEPA Determination.

161. Sayyah A, Horenstein M, Mazumder M, Ahmadi G. Electrostatic Force Distribution on an Electrodynamic Screen. J. Electrost. 2016;81:24-36.

162. Kawamoto $\mathrm{H}$. Improved detachable electrodynamic cleaning system for dust removal from soiled photovoltaic panels. J. Electrost. 2020;107:103481.

163. Javed W, Guo B. Effect of relative humidity on dust removal performance of electrodynamic dust shield. J. Electrost. 2020;105:103434.

164. Bernard A, Eriksen R, Mazumder M. Development of Hybrid Structures of Silver Nanowire Electrodes for the Electrodynamic Screen (EDS) Films to Mitigate Energy Yield Loss Incurred by Solar Collectors Due to Soiling. MRS Adv. 2019;4:343-350.

165. Bieg KW, Wischmann KB. Plasma-polymerized organosilanes as protective coatings for solar front-surface mirrors. Sol. Energy Mater. 1980;3:301-316.

166. Polizos G, Schaeffer DA, Smith DB, Lee DF, Datskos PG, Hunter SR. Enhanced Durability Transparent Superhydrophobic Anti-Soiling Coatings for CSP Applications. In: ASME 2014 8th International Conference on Energy; 30 June-2 July 2014: Boston, Massachusetts. p. ES2014-6505.

167. Aranzabe E, Azpitarte I, Fernández-García A, et al. Hydrophilic anti-soiling coating for improved efficiency of solar reflectors. AIP Conf. Proc. 2018;2033:220001.

168. Lorenz T, Klimm E, Weiss KA. Soiling and Anti-soiling Coatings on Surfaces of Solar Thermal Systems - Featuring an Economic Feasibility Analysis. Energy Procedia 2014;48: 749-756.

169. Wiesinger F, Vicente GS, Fernández-García A, Sutter F, Pitz-Paal R. Sandstorm erosion testing of anti-reflective glass coatings for solar energy applications. Sol. Energy Mater. Solar Cells 2018;179:10-16.

170. Wette J, Fernández-García A, Sutter F, et al. Water Saving in CSP Plants by a Novel Hydrophilic Anti-Soiling Coating for Solar Reflectors. Coatings 2019;9:739.

171. Fernández-García A, Aranzabe E, Azpitarte I, et al. Durability testing of a newly developed hydrophilic anti-soiling coating for solar reflectors. AIP Conf. Proc. 2019;2126:160002.

172. Matal A, Naamane S. Accelerated erosion of coated solar glass reflectors. AIP Conf. Proc. 2020;2303:150012.

173. Wette J, Sutter F, Fernández-García A. Evaluation of anti-soil- 
ing coatings for CSP reflectors under realistic outdoor conditions. Sol. Energy 2019;191:574-584.

174. Lopes D, Conceição R, Silva HG, Aranzabe E, Pérez G, Pereira MC. Anti-soiling coating performance assessment on the reduction of soiling in 2nd-surface solar mirror. Sol. Energy 2019;194:478-484.

175. Pescheux AC, Raccurt O, Bourdon D, Le-Baron E. Accelerated aging tests and characterizations of innovated anti-soiling coatings for solar receiver glasses. Mater. Chem. Phys. 2020;256:123646.

176. Sutter F, Reche-Navarro TJ, Vicente GS, Fernández-García A. Durability of anti-reflective coatings for parabolic trough receivers. AIP Conf. Proc. 2020;2303:150015.

177. Wette J, Sutter F, Buendía-Martínez F, Fernández-García A. Effect of long term outdoor exposure on anti-soiling coatings for solar reflectors. AIP Conf. Proc. 2020;2303:150016.
178. Yilbas BS, Hassan G, Al-Qahtani H, Al-Sharafi A, Sahin AZ. Dust mitigation by rolling water droplets from hydrophobic surfaces. Surf. Interfaces 2021;22:100825.

179. Kazem HA, Chaichan MT. The effect of dust accumulation and cleaning methods on PV panels' outcomes based on an experimental study of six locations in Northern Oman. Sol. Energy 2019;187:30-38.

180. Alnasser TMA, Mahdy AMJ, Abass KI, Chaichan MT, Kazem HA. Impact of dust ingredient on photovoltaic performance: An experimental study. Sol. Energy 2020;195:651-659.

181. Liu Y, Huang J, Takamura T, et al. Aerosol optical properties and radiative effect determined from sky-radiometer over Loess Plateau of Northwest China. Atmos. Chem. Phys. 2011;11:11455.

182. Angström A. On the Atmospheric Transmission of Sun Radiation and on Dust in the Air. Geogr. Ann. 1929;2:156-166. 